\title{
Consideraciones sobre el calzado de época romana y tardoantigua en la región septentrional de la Península Ibérica
}

\section{Concerning the Roman and Late Antiquity Footwear in Northern Iberia}

\author{
Carmen Fernández Ochoa ${ }^{1}$ \\ Ángel Morillo Cerdán ${ }^{2}$ \\ Javier Salido Domínguez'
}

\section{Resumen}

En este artículo se analizan los fragmentos de cuero correspondientes a diferentes tipos de calzado localizados en el norte de la Península Ibérica. El objetivo es ofrecer un estudio de conjunto que nos permite establecer las técnicas de fabricación y las tipologías, así como reconocer los cambios que atañen al calzado en la fase de transición entre la época clásica y tardoantigua hasta el periodo altomedieval.

Palabras clave: peletería, indumentaria, calzado, cuero, depósitos de agua, pozos, salinas.

\begin{abstract}
In this article we analyze leather fragments corresponding to different types of footwear located in Northern Iberia. The objective is to offer an overall study that allows us to establish the manufacturing techniques and typologies, as well as to recognize the changes that affect the footwear between the Roman period and Late Antiquity until the Early Medieval period.
\end{abstract}

Keywords: fur, clothing, footwear, leather, water tanks, wells, salt pans.

\section{El CAlZado en ÉPOCA Romana y taRdoantigua EN HISPANIA}

El trabajo del cuero y en concreto la elaboración de zapatos en la Antigüedad Clásica y durante el periodo tardoantiguo apenas ha sido objeto de atención por los especialistas que han trabajo sobre materiales arqueológicos de Hispania, quedando relegada la información a someras descripciones y simples indicaciones de restos materiales en las memorias de excavación. A pesar de la información tan precisa que nos aportan estos elementos de indumentaria sobre la vida cotidiana, los gustos y las modas, además de la diferencia social que implican, no contamos en la bibliografía con ninguna publicación dedicada a su estudio. Esta ausencia de investigaciones contrasta con la información procedente de contextos

Departamento de Prehistoria y Arqueología. Universidad Autónoma de Madrid. carmen.fernandez@uam.es

2 Departamento de Ciencias y Técnicas Historiográficas y de Arqueología. Universidad Complutense de Madrid. del norte de Europa donde hay una mayor tradición historiográfica sobre el trabajo del cuero ${ }^{3}$. Los numerosos hallazgos de restos de calzado de diferente tipo y variedad en las provincias septentrionales del Imperio romano han permitido establecer incluso una tipología en función de la evolución de la colocación de las tachuelas en el caso de las caligae y determinar unos marcos cronológicos para los diferentes tipos de calzado (Van Driel-Murray, 2001) (fig. 1) y fijar unos criterios de identificación arqueológicos para definir la tipología de los zapatos, distinguidos con al menos 15 términos latinos, algunos apenas conocidos a nivel arqueológico (Leguilloux, 2004: 97). Estos análisis y tipologías son los que nos permiten en la

\footnotetext{
Entre los numerosos estudios podemos destacar los trabajos de Fremersdorf, 1926; Gansser-Burckhard, 1942; Van Driel-Murray, 1965, 1977, 1977b, 1999, 1999b, 2001, 2001b; Groenman-Van Waateringe, 1967; Hald, 1972; Charlesworth y Thornton, 1973; Macgregor, 1978; Rhodes, 1980; Schleiermacher, 1982; Macconnoran, 1986; Rhodes, 1986; Padley y Winterbottom, 1991; Goldman, 1994; Mould, 1997; Mould et al., 2003; Leguilloux, 2004; Chabal y Feugère, 2005; Gräf, 2009; Vanhoutte et al., 2009; Fiches, 2012.
} 


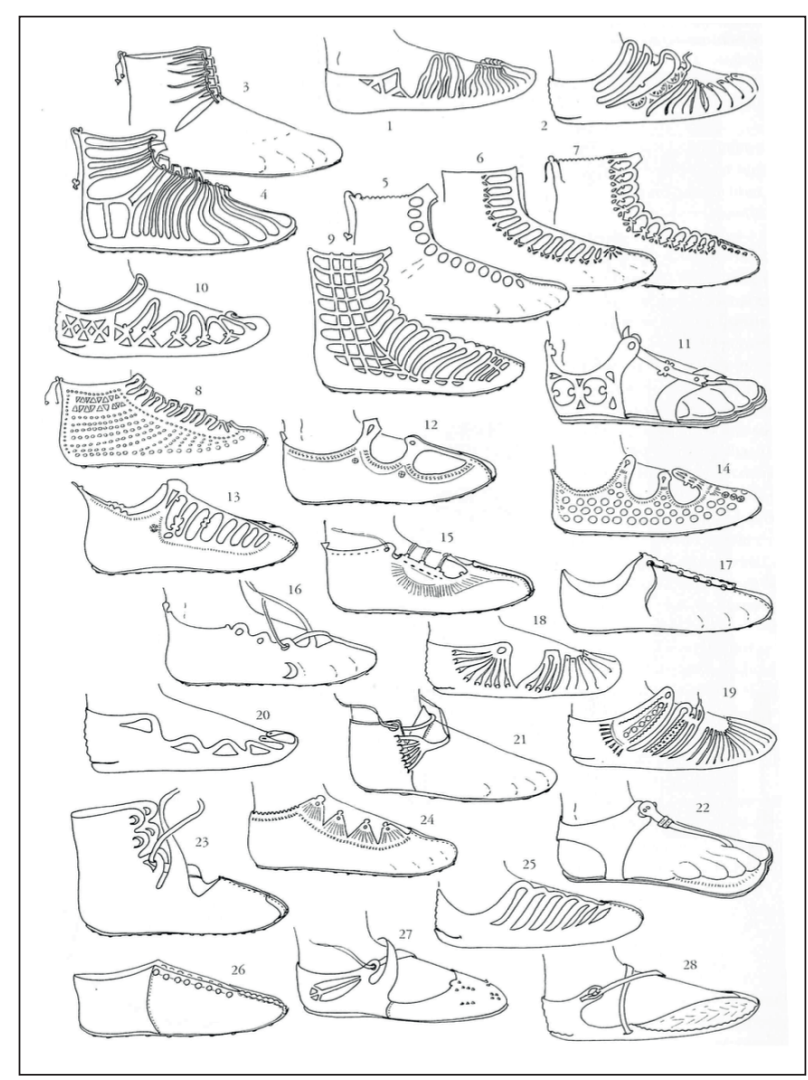

Figura 1. Evolución del calzado desde el siglo I d.C. (arriba izquierda) al siglo IV d.C. (abajo derecha), según Van Driel-Murray (2001: fig. 10).

actualidad clasificar el material que aquí analizamos con el fin de completar el mapa de dispersión del calzado en la Hispania romana y tardoantigua.

La escasa presencia de un material tan perecedero como el cuero en el registro arqueológico también explica la ausencia de estudios y análisis particulares sobre estos objetos. Los problemas de conservación del cordaje y el cuero con el que se fabricó el calzado en contextos arqueológicos de la Península Ibérica, donde predominan suelos ácidos y secos y con escasa cobertura de tierra, ha determinado que estos objetos hayan desaparecido casi por completo, a diferencia de países como Alemania, Gran Bretaña, Suiza, Países Bajos o el norte de Francia, donde la humedad y las características edafológicas ${ }^{4}$ los han preservado mucho mejor.

Además de los restos de calzado de cuero procedentes de la región septentrional peninsular, se ha localizado un ejemplar más en el interior de una fuente monumental de Tarraco (Tarragona) (Pociña y Remolá, 2002: 45, fig. 8), así como las suelas de cuero localizadas en una sepultura romana de Ontur (Albacete) (Comisaría General de Excavaciones Arqueológicas. Informes y memorias $\mathrm{n}^{\mathrm{o}} 15$, 1, 73; García y Bellido, 1979: 167). Una cuestión aparte

4 Sobre la conservación de productos orgánicos perecederos en la Península Iberica, v. Morillo et al., 2018: e. p. es la documentación de calzado a partir de las tachuelas de cáliga o clavi caligarii localizadas tanto en caminos como en contexto funerario, tema que no abordaremos en este trabajo. Recientemente se ha dado a conocer la aparición de una sandalia en una de las estructuras funerarias encontradas en la calle de Sant Antoni Abat, del barrio de El Raval en Barcelona, correspondiente muy probablemente al área de necrópolis situada a lo largo del trazado de la vía romana que atravesaba la ciudad. En una de esas sepulturas, una tumba en caja de tejas, apareció parte del ajuar del difunto, del que se conservan restos de su calzado, concretamente las tachuelas (clavi caligarii) de la suela claveteada, fechada en el siglo II d.C. (El País-Cataluña, 29 de febrero de 2012). En contexto funerario, se conocen también los clavi caligarii de la necrópolis de Paredes (Siero, Asturias) (Requejo, 2000), así como del cementerio de la Dehesa del Pontón de la Oliva (Madrid) (Muñoz, 1994: 41), de la calle Gerona ${ }^{\circ}$ 4 de Móstoles (Galindo y Sánchez, 2005: 75), en la necrópolis del Jardín P10 (Arroyomolinos, Madrid) y Cabriana (Burgos) (cf. Vigil-Escalera, 2015: 209), en la necrópolis norte de la Olmeda (Palencia) (Abásolo et al., 1997), Las Merchanas (Salamanca) (Maluquer, 1968), Fuentespreadas (Zamora) (Caballero, 1974), Toletum (Palol, 1972: 133 y 138), Santa María de Hito (Gutiérrez y Hierro, 2009: 413), Tiermes y El Vergel (Ávila) (Serrulla et al., 2011). Este tipo de hallazgos son frecuentes también en otras regiones del Imperio Romano (Le Forestier, 2013). A finales del siglo V d. C. se documentan en las necrópolis de Aldaieta (Azkarate, 1999) y San Martín de Dulantzi (Loza y Niso, 2011).

También es digno de destacar el repertorio de tachuelas aparecido en el campo de batalla de Andagoste, datado en torno al año 38 a.C. (Unzueta y Ocharán, 2006), en Santo Tomé, probable escenario de la batalla de Baecula (Ruiz Rodríguez et al., 2013; Quesada et al., 2015), y en castros y estructuras de asedio de las Guerras Cántabras, como en el Alto de la Espina del Gallego y Cildá, Alto de Castillejo, el campamento romano de La Muela y en Las Cercas (cf. Peralta, 2000), así como en el campamento de El Alambre (Fuencaliente de Lucio, Burgos) (Peralta et al., 2011, fig. 17, 63 y 64) y en las estructuras defensivas de Robadorio (Serna y Gómez, 2010: 123), Retorín (Pablos, 2010) y del castro del Castillo de Prellezo (Serna, 2010: 181) en Cantabria. En las calzadas también aparecen perdidas como en el tramo del puente de Becilla de Valderaduey (Valladolid) (Morillo et al., 2010, 74-75, fig. 38), o en la vía de los Vasos de Vicarello, en el Campo de Montiel (Ciudad Real) (Rodríguez Morales et al., 2012). Se localizó también un repertorio de 51 tachuelas correspondientes a un calzado en la villa de Priañes (Nora, Oviedo) (Requejo y Martínez, 2000: 407-408).

La presencia del calzado también se puede constatar a partir de las huellas e improntas realizadas sobre los ladrillos cuando éstos estaban húmedos. Es el caso de los ladrillos bipedales de la legio VII gemina en León (García y Bellido, 1966: 15-25, 1979: 576-577) y de los ladrillos pedales (Morillo y Salido, 2013: 151 y 166, nº 6, fig. 4), o 


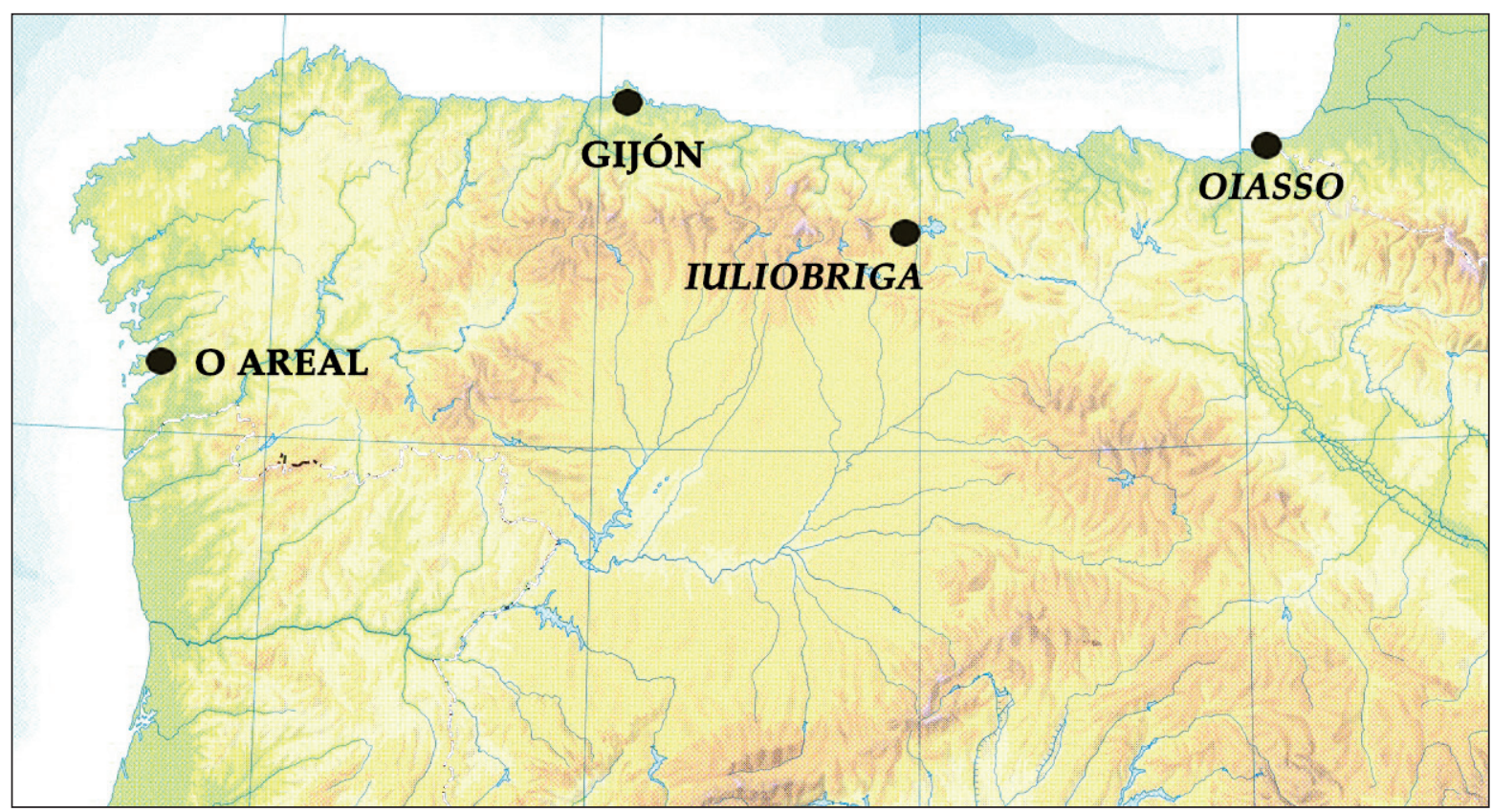

Figura 2. Mapa de dispersión de cuero de calzado de la región septentrional de Hispania romana y tardoantigua.

las marcas sobre material latericio del campamento romano de Cidadela (Sobrado dos Monxes, A Coruña) (Carlsson-Brant, 2011: 172 y 177). Además de estas, tenemos constancia de la impronta de huellas sobre ladrillos en contexto civil como la pisada en el interior de la cueva de Román (Burgos) (Rodríguez Ceballos, 2016), la infantil sobre un ladrillo aparecido en el yacimiento de El Rasillo (Madrid) (Vigil-Escalera, 2015: 209, fig. 48), la conservada en el Museo Arqueológico de Astorga y otra en el de Sevilla, un más sobre un suelo sin fraguar en Carranque (Toledo), varias en Valeria (Cuenca), Simancas (Valladolid), Toledo, el castro de La Lanzada (Pontevedra) o el asentamiento rural del Salto de la Novia (Ulea, Murcia) (cf. Rodríguez Morales et al., 2012: 156). También en contexto funerario se documentan en posición secundaria sobre ladrillos empleados en la cubrición de las tumbas, como en San Miguel del Arroyo (Valladolid) (Palol, 1958).

\section{Catálogo y contexto arqueológico}

Los fragmentos de cuero correspondientes a diferentes tipos de calzado localizados en el norte peninsular proceden de diferentes contextos que guardan entre sí unas condiciones ambientales similares que han permitido la conservación de los materiales orgánicos perecederos (figs. 2 y 3 ).

\subsection{Iuliobriga (Campoo de Enmedio, Cantabria)}

Los ejemplares de calzado que se conocen desde mediados del siglo XX proceden del interior de un pozo localizado en la ciudad romana de Iuliobriga (Campoo de Enmedio, Cantabria) (fig. 4). Según la información aportada por García y Bellido (1957: 166-167, fig. 54 y 55) se hallaron cuatro suelas y restos de la parte superior de una de ellas $\left(\mathrm{n}^{0} 5-8\right)$. Apenas contamos con más información que esta, puesto que por desgracia, fueron pasto de las llamas en un incendio producido en la sede del CSIC de Madrid (Calle Medinaceli) cuando se hallaban en el despacho de don Antonio García y Bellido ${ }^{5}$. El material asociado al calzado ha permitido datarlos en los siglos I-II d.C. (García y Bellido, 1957: 149-150).

\subsection{Salinas de O Areal (Vigo, Pontevedra)}

De las salinas romanas de O Areal (Vigo, Pontevedra), proceden más ejemplares de zapatos claveteados, cosidos, además de una sandalia $\left(\mathrm{n}^{\mathrm{o}} 11\right)$, tal y como se muestran en el trabajo de Benavides (2010: 352) (figs. 5-7). Las intervenciones arqueológicas realizadas desde el año 2006 en el emplazamiento conocido como Unidad de Actuación Rosalía de Castro II (UARC II) o Sector Oriental de la salina han localizado diversos estanques y una secuencia ocupacional que abarca desde la protohistoria hasta la actualidad, con una importante presencia en época romana y tardoantigua en la que se pueden diferenciar varias fases (Castro Carrera et al., 2017). Durante

5 Agradecemos la información a Javier Arce que nos lo indicó oralmente en el IV SEOA: Veinticinco estampas de la España antigua cincuenta años después, congreso celebrado en Madrid en torno a la figura de A. García y Bellido los días 15 y 16 de marzo de 2017 en Madrid. 


\begin{tabular}{|c|c|c|c|c|c|c|c|c|}
\hline $\mathbf{N}^{0}$ & Yacimiento & Contexto & Ejemplar & Cronología & Dimensiones & $\begin{array}{c}\text { Estado de } \\
\text { conservación }\end{array}$ & Características & Bibliografía \\
\hline 1 & $\begin{array}{l}\text { Gijón, Fábrica } \\
\text { de Tabacos } \\
\text { (Asturias) }\end{array}$ & $\begin{array}{l}\text { Interior de un } \\
\text { depósito }\end{array}$ & TB09-20-82-13 & $\begin{array}{l}\text { Datación C-14: } \\
\text { 588-691 d. C. }\end{array}$ & & $\begin{array}{l}\text { Bastante completa y } \\
\text { deformada. Presenta } \\
\text { restos del cordaje. }\end{array}$ & $\begin{array}{l}\text { La forma del calzado } \\
\text { es apuntada y } \\
\text { presenta tachuelas } \\
\text { en la planta. } \\
\text { Corresponde al pie } \\
\text { izquierdo. }\end{array}$ & $\begin{array}{l}\text { Fernández } \\
\text { Ochoa et alii } \\
\text { 2015: 138-139. }\end{array}$ \\
\hline 2 & $\begin{array}{l}\text { Gijón, Fábrica } \\
\text { de Tabacos } \\
\text { (Asturias) }\end{array}$ & $\begin{array}{l}\text { Interior de un } \\
\text { depósito }\end{array}$ & TB/09.20.83F.27 & $\begin{array}{l}\text { Datación C-14: } \\
\text { 660-820 d. C. }\end{array}$ & $10 \times 8 \mathrm{~cm}$ & No conserva el talón. & $\begin{array}{l}\text { Corresponde al pie } \\
\text { izquierdo. }\end{array}$ & $\begin{array}{l}\text { Fernández } \\
\text { Ochoa et alii } \\
\text { 2015: 138-139. }\end{array}$ \\
\hline 3 & $\begin{array}{l}\text { Gijón, Fábrica } \\
\text { de Tabacos } \\
\text { (Asturias) }\end{array}$ & $\begin{array}{l}\text { Interior de un } \\
\text { depósito }\end{array}$ & TB/09.20.83F.51 & $\begin{array}{l}\text { Datación C-14: } \\
\text { 600-690 d. C. }\end{array}$ & $10,5 \times 9,5 \mathrm{~cm}$ & $\begin{array}{l}\text { Se ha conservado solo } \\
\text { la parte central de la } \\
\text { suela. }\end{array}$ & & $\begin{array}{l}\text { Fernández } \\
\text { Ochoa et alii } \\
\text { 2015: 138-139. }\end{array}$ \\
\hline 4 & $\begin{array}{l}\text { Gijón, Fábrica } \\
\text { de Tabacos } \\
\text { (Asturias) }\end{array}$ & $\begin{array}{l}\text { Interior de un } \\
\text { depósito }\end{array}$ & TB/09.20.83F.39 & $\begin{array}{l}\text { Por contexto: } \\
\text { VII d. C. }\end{array}$ & $10,5 \times 8,5 \mathrm{~cm}$ & $\begin{array}{l}\text { Mal estado de } \\
\text { conervación. }\end{array}$ & & $\begin{array}{l}\text { Fernández } \\
\text { Ochoa et alii } \\
\text { 2015: 138-139. }\end{array}$ \\
\hline 5 & $\begin{array}{l}\text { Iuliobriga } \\
\text { (Campoo de } \\
\text { En medio, } \\
\text { Cantabria) } \\
\end{array}$ & Interior de un pozo & Suela 1 & Siglos I-II d.C. & $15 \times 5 \mathrm{~cm}$ & $\begin{array}{l}\text { No conserva ni el talón } \\
\text { ni la puntera. }\end{array}$ & $\begin{array}{l}\text { Presenta tachuelas } \\
\text { en la planta. } \\
\text { Corresponde al pie } \\
\text { derecho. }\end{array}$ & $\begin{array}{l}\text { García y Bellido } \\
\text { 1957: } 166-167, \\
\text { fig. } 54 \text { y } 55 .\end{array}$ \\
\hline 6 & \begin{tabular}{|l} 
Iuliobriga \\
(Campoo de \\
En medio, \\
Cantabria) \\
\end{tabular} & Interior de un pozo & Suela 2 & Siglos I-II d.C. & $8 \times 5 \mathrm{~cm}$ & No conserva el talón. & Calzado infantil. & $\begin{array}{l}\text { García y Bellido } \\
\text { 1957: } 166-167 \text {, } \\
\text { fig. } 54 \text { y } 55 .\end{array}$ \\
\hline 7 & $\begin{array}{l}\text { Iuliobriga } \\
\text { (Campoo de } \\
\text { En medio, } \\
\text { Cantabria) }\end{array}$ & Interior de un pozo & Suela 3 & Siglos I-II d.C. & $17 \times 7 \mathrm{~cm}$ & $\begin{array}{l}\text { Se conserva bastante } \\
\text { completa. }\end{array}$ & $\begin{array}{l}\text { Presenta marcas de } \\
\text { cosido. Corresponde } \\
\text { al pie izquierdo. }\end{array}$ & $\begin{array}{l}\text { García y Bellido } \\
\text { 1957: } 166-167 \text {, } \\
\text { fig. } 54 \text { y } 55 .\end{array}$ \\
\hline 8 & $\begin{array}{l}\text { Iuliobriga } \\
\text { (Campoo de } \\
\text { En medio, } \\
\text { Cantabria) } \\
\end{array}$ & Interior de un pozo & Suela 4 & Siglos I-II d.C. & & $\begin{array}{l}\text { Se ha conservado solo } \\
\text { la parte central de la } \\
\text { suela. }\end{array}$ & & $\begin{array}{l}\text { García y Bellido } \\
\text { 1957: 166-167, } \\
\text { fig. } 54 \text { y } 55 .\end{array}$ \\
\hline 9 & $\begin{array}{l}\text { O Areal (Vigo, } \\
\text { Galicia) }\end{array}$ & $\begin{array}{l}\text { Salinas romanas C/ } \\
\text { Rosalía de Castro }\end{array}$ & $\begin{array}{l}\text { Calzado cosido } \\
\text { completo }\end{array}$ & $\begin{array}{l}\text { Siglos I-II d. C. } \\
\text { e inicios del III } \\
\text { d. C. }\end{array}$ & & $\begin{array}{l}\text { Se conserva casi } \\
\text { completo. }\end{array}$ & $\begin{array}{l}\text { Corresponde al pie } \\
\text { derecho. }\end{array}$ & $\begin{array}{l}\text { Benavides } \\
\text { 2010: } 352 .\end{array}$ \\
\hline 10 & $\begin{array}{l}\text { O Areal (Vigo, } \\
\text { Galicia) }\end{array}$ & $\begin{array}{l}\text { Salinas romanas } \mathrm{C} / \\
\text { Rosalía de Castro }\end{array}$ & Suela claveteada & $\begin{array}{l}\text { Siglos I-II d. C. } \\
\text { e inicios del III } \\
\text { d. C. } \\
\end{array}$ & & $\begin{array}{l}\text { Se conserva casi } \\
\text { completa. }\end{array}$ & $\begin{array}{l}\text { Corresponde al pie } \\
\text { izquierdo. }\end{array}$ & $\begin{array}{l}\text { Benavides } \\
\text { 2010: } 352 .\end{array}$ \\
\hline 11 & $\begin{array}{l}\text { O Areal (Vigo, } \\
\text { Galicia) }\end{array}$ & $\begin{array}{l}\text { Salinas romanas C/ } \\
\text { Rosalía de Castro }\end{array}$ & $\begin{array}{l}\text { Suela de } \\
\text { sandalia (solea) }\end{array}$ & $\begin{array}{l}\text { Siglos I-II d. C. } \\
\text { e inicios del III } \\
\text { d. C. } \\
\end{array}$ & & $\begin{array}{l}\text { Se conserva casi } \\
\text { completa. }\end{array}$ & $\begin{array}{l}\text { Corresponde al pie } \\
\text { izquierdo. }\end{array}$ & $\begin{array}{l}\text { Benavides } \\
\text { 2010: } 352 .\end{array}$ \\
\hline 12 & $\begin{array}{l}\text { Oiasso (Irún, } \\
\text { País Vasco) }\end{array}$ & $\begin{array}{l}\text { Complejo portuario } \\
\text { de Tadeo Murgia, } \\
\text { Irún. Código de } \\
\text { referencia: TMI } 98 .\end{array}$ & TMI 98, 125 & $\begin{array}{l}70 \text { d.C.- siglo II } \\
\text { d. C. }\end{array}$ & $\begin{array}{l}23,2 \text { x } 10,1 \\
\mathrm{~cm} \text {; grosor: } \\
0,1 \mathrm{~cm}\end{array}$ & $\begin{array}{l}\text { Ha perdido la punta y } \\
\text { el talón, pero conserva } \\
\text { dos capas de cuero y } \\
\text { restos del cordaje. }\end{array}$ & $\begin{array}{l}\text { Corresponde al pie } \\
\text { derecho. Presenta } \\
\text { tachuelas en la } \\
\text { planta. }\end{array}$ & $\begin{array}{l}\text { Urteaga y } \\
\text { Alkaín } 2017 .\end{array}$ \\
\hline 13 & $\begin{array}{l}\text { Oiasso (Irún, } \\
\text { País Vasco) }\end{array}$ & $\begin{array}{l}\text { Complejo portuario } \\
\text { de Tadeo Murgia, } \\
\text { Irún. Código de } \\
\text { referencia: TMI } 98 .\end{array}$ & TMI 98, 135 & $\begin{array}{l}70 \text { d.C.- siglo II } \\
\text { d. C. }\end{array}$ & $\begin{array}{l}10,2 \times 7,15 \\
\mathrm{~cm} \text {; grosor: } \\
0,3 \mathrm{~cm} .\end{array}$ & $\begin{array}{l}\text { Presenta en la parte } \\
\text { lateral de la punta } \\
\text { el borde recortado } \\
\text { imitando tres dedos; el } \\
\text { resto de la punta está } \\
\text { rasgada. Sólo se ha } \\
\text { conservado la zona de } \\
\text { la puntera. } \\
\end{array}$ & $\begin{array}{l}\text { Suela de sandalia } \\
\text { o solea infantil. } \\
\text { Corresponde al pie } \\
\text { derecho. Presenta } \\
\text { marcas de cosido. }\end{array}$ & $\begin{array}{l}\text { Urteaga y } \\
\text { Alkaín } 2017 .\end{array}$ \\
\hline 14 & $\begin{array}{l}\text { Oiasso (Irún, } \\
\text { País Vasco) }\end{array}$ & $\begin{array}{l}\text { Complejo portuario } \\
\text { de Tadeo Murgia, } \\
\text { Irún. Código de } \\
\text { referencia: TMI } 98 .\end{array}$ & TMI 98, 178 & $\begin{array}{l}70 \text { d.C.- siglo II } \\
\text { d. C. }\end{array}$ & $\begin{array}{l}21,2 \text { x } 9,8 \\
\mathrm{~cm} \text {; grosor: } \\
0,1 \mathrm{~cm}\end{array}$ & $\begin{array}{l}\text { Ha perdido la punta, } \\
\text { pero conserva cuatro } \\
\text { capas de cuero. }\end{array}$ & $\begin{array}{l}\text { Corresponde al pie } \\
\text { derecho. Presenta } \\
\text { tachuelas en la } \\
\text { planta. }\end{array}$ & $\begin{array}{l}\text { Urteaga y } \\
\text { Alkaín } 2017 .\end{array}$ \\
\hline 15 & $\begin{array}{l}\text { Oiasso (Irún, } \\
\text { País Vasco) }\end{array}$ & $\begin{array}{l}\text { Complejo portuario } \\
\text { de Tadeo Murgia, } \\
\text { Irún. Código de } \\
\text { referencia: TMI } 98 .\end{array}$ & TMI 98, 226 & $\begin{array}{l}70 \text { d.C.- siglo II } \\
\text { d. C. }\end{array}$ & $\begin{array}{l}20 \times 9,25 \\
\mathrm{~cm} \text {; grosor: } \\
0,3 \mathrm{~cm} .\end{array}$ & $\begin{array}{l}\text { Se ha conservado } \\
\text { en } 2 \text { fragmentos. } \\
\text { Conserva } 42 \text { orificios } \\
\text { redondeados, indicando } \\
\text { la posición de las } \\
\text { tachuelas que llegan } \\
\text { a tener hasta } 8 \mathrm{~mm} \text { de } \\
\text { diámetro. }\end{array}$ & $\begin{array}{l}\text { Suela de calzado } \\
\text { claveteado, con } \\
\text { extremo apuntado } \\
\text { Corresponde al pie } \\
\text { derecho. }\end{array}$ & $\begin{array}{l}\text { Urteaga y } \\
\text { Alkaín } 2017 .\end{array}$ \\
\hline
\end{tabular}

Figura 3. Tabla comparativa del calzado analizado (Continúa). 


\begin{tabular}{|c|c|c|c|c|c|c|c|c|}
\hline $\mathbf{N}^{0}$ & Yacimiento & Contexto & Ejemplar & Cronología & Dimensiones & $\begin{array}{c}\text { Estado de } \\
\text { conservación }\end{array}$ & Características & Bibliografía \\
\hline 16 & $\begin{array}{l}\text { Oiasso (Irún, } \\
\text { País Vasco) }\end{array}$ & $\begin{array}{l}\text { Complejo portuario } \\
\text { de Tadeo Murgia, } \\
\text { Irún. Código de } \\
\text { referencia: TMI } 98 .\end{array}$ & TMI 98, 531 & $\begin{array}{l}70 \text { d.C.- siglo II } \\
\text { d. C. }\end{array}$ & $\begin{array}{l}8 \times 3,6 \mathrm{~cm} \\
\text { grosor: } \\
0,3 \mathrm{~cm} .\end{array}$ & $\begin{array}{l}\text { Sólo se ha conservado } \\
\text { la mitad derecha del } \\
\text { enfranque, faltando } \\
\text { la puntera y el } \\
\text { talón. Se registran } 5 \\
\text { orificios de } 2 \text { mm que } \\
\text { indican la posición } \\
\text { de los vástagos de las } \\
\text { tachuelas. }\end{array}$ & $\begin{array}{l}\text { Suela de calzado } \\
\text { claveteado. } \\
\text { Corresponde al pie } \\
\text { derecho. }\end{array}$ & $\begin{array}{l}\text { Urteaga y } \\
\text { Alkaín } 2017 .\end{array}$ \\
\hline 17 & $\begin{array}{l}\text { Oiasso (Irún, } \\
\text { País Vasco) }\end{array}$ & $\begin{array}{l}\text { Complejo portuario } \\
\text { de Tadeo Murgia, } \\
\text { Irún. Código de } \\
\text { referencia: TMI } 98 .\end{array}$ & TMI 98, 539 & $\begin{array}{l}70 \text { d.C.- siglo II } \\
\text { d. C. }\end{array}$ & $\begin{array}{l}27 \times 10 \mathrm{~cm} ; \\
\text { grosor: } 0,2 \mathrm{~cm}\end{array}$ & $\begin{array}{l}\text { Se ha conservado en } \\
\text { cuatro fragmentos. } \\
\text { Falta parte del lateral } \\
\text { izquierdo y de la zona } \\
\text { del tacón. Presenta } 48 \\
\text { orificios redondos, que } \\
\text { llegan a tener hasta } 10 \\
\text { mm de diámetro. } \\
\end{array}$ & $\begin{array}{l}\text { Suela de calzado } \\
\text { claveteado. } \\
\text { Corresponde al pie } \\
\text { derecho. Tiene el } \\
\text { extremo apuntado. }\end{array}$ & $\begin{array}{l}\text { Urteaga y } \\
\text { Alkaín } 2017 .\end{array}$ \\
\hline 18 & $\begin{array}{l}\text { Oiasso (Irún, } \\
\text { País Vasco) }\end{array}$ & $\begin{array}{l}\text { Complejo portuario } \\
\text { de Tadeo Murgia, } \\
\text { Irún. Código de } \\
\text { referencia: TMI } 98 .\end{array}$ & TMI 98, 541. & $\begin{array}{l}70 \text { d.C.- siglo II } \\
\text { d. C. }\end{array}$ & $15 \times 5,5 \mathrm{~cm}$. & $\begin{array}{l}\text { Sólo se conserva la } \\
\text { mitad del enfranque, } \\
\text { habiendo desaparecido } \\
\text { la punta y el talón. } \\
\text { Consta de } 2 \text { capas. }\end{array}$ & $\begin{array}{l}\text { Suela de calzado } \\
\text { claveteado. } \\
\text { Corresponde al pie } \\
\text { izquierdo. }\end{array}$ & $\begin{array}{l}\text { Urteaga y } \\
\text { Alkaín } 2017 .\end{array}$ \\
\hline 19 & $\begin{array}{l}\text { Oiasso (Irún, } \\
\text { País Vasco) }\end{array}$ & $\begin{array}{l}\text { Complejo portuario } \\
\text { de calle Santiago. } \\
\text { Código de } \\
\text { referencia: CSI } 92 .\end{array}$ & CSI 92, 40. & $\begin{array}{l}70 \text { d.C.- siglo II } \\
\text { d. C. }\end{array}$ & $\begin{array}{l}22 \times 7,5 \mathrm{~cm} \\
\text { grosor: } 0,3 \mathrm{~m} .\end{array}$ & $\begin{array}{l}\text { Calzado compuesto } \\
\text { por tres piezas, unidas } \\
\text { mediante cosido. Falta } \\
\text { parte de un lateral. }\end{array}$ & $\begin{array}{l}\text { Suela de calzado } \\
\text { cosido. Corresponde } \\
\text { al pie derecho de } \\
\text { un calzado infantil. } \\
\text { Presenta extremo } \\
\text { apuntado. Presenta } \\
\text { marcas de cosido. }\end{array}$ & $\begin{array}{l}\text { Urteaga y } \\
\text { Alkaín } 2017 .\end{array}$ \\
\hline 20 & $\begin{array}{l}\text { Oiasso (Irún, } \\
\text { País Vasco) }\end{array}$ & $\begin{array}{l}\text { Complejo portuario } \\
\text { de calle Santiago. } \\
\text { Código de } \\
\text { referencia: CSI } 92 .\end{array}$ & CSI 92, 46 & $\begin{array}{l}70 \text { d.C.- siglo II } \\
\text { d. C. }\end{array}$ & $\begin{array}{l}14,7 \text { x } 7 \mathrm{~cm} ; \\
\text { grosor: } 0,2 \\
\mathrm{~cm} .\end{array}$ & $\begin{array}{l}\text { Presenta en el lateral } \\
\text { exterior de la punta } \\
\text { el borde recortado } \\
\text { imitando tres dedos. Se } \\
\text { ha conservado en dos } \\
\text { fragmentos. }\end{array}$ & $\begin{array}{l}\text { Suela de sandalia } \\
\text { o solea infantil. } \\
\text { Corresponde al pie } \\
\text { izquierdo. Presenta } \\
\text { marcas de cosido. }\end{array}$ & $\begin{array}{l}\text { Urteaga y } \\
\text { Alkaín } 2017 .\end{array}$ \\
\hline 21 & $\begin{array}{l}\text { Oiasso (Irún, } \\
\text { País Vasco) }\end{array}$ & $\begin{array}{l}\text { Complejo portuario } \\
\text { de calle Santiago. } \\
\text { Código de } \\
\text { referencia: CSI } 92 .\end{array}$ & CSI 92, 55. & $\begin{array}{l}70 \text { d.C.- siglo II } \\
\text { d. C. }\end{array}$ & $\begin{array}{l}16,5 \text { x } 6 \mathrm{~cm} ; \\
\text { grosor: } 0,2 \\
\mathrm{~cm} .\end{array}$ & $\begin{array}{l}\text { Falta parte del talón y } \\
\text { de la puntera. }\end{array}$ & $\begin{array}{l}\text { Plantilla de calzado } \\
\text { infantil. Corresponde } \\
\text { al pie derecho. } \\
\text { Presenta marcas de } \\
\text { cosido. }\end{array}$ & $\begin{array}{l}\text { Urteaga y } \\
\text { Alkaín } 2017 .\end{array}$ \\
\hline 22 & $\begin{array}{l}\text { Oiasso (Irún, } \\
\text { País Vasco) }\end{array}$ & $\begin{array}{l}\text { Complejo portuario } \\
\text { de calle Santiago. } \\
\text { Código de } \\
\text { referencia: CSI } 92 .\end{array}$ & CSI 92, 56 & $\begin{array}{l}70 \text { d.C.- siglo II } \\
\text { d. C. }\end{array}$ & $\begin{array}{l}15 \times 5,5 \mathrm{~cm} \\
\text { de anchura } \\
\text { máxima. } \\
\text { Grosor: } 2 \mathrm{~mm}\end{array}$ & $\begin{array}{l}\text { La punta está } \\
\text { incompleta pero } \\
\text { se aprecia el borde } \\
\text { recortado imitando la } \\
\text { forma de un dedo. }\end{array}$ & $\begin{array}{l}\text { Suela de sandalia } \\
\text { o solea infantil. } \\
\text { Corresponde al pie } \\
\text { derecho. Presenta } \\
\text { marcas de cosido. }\end{array}$ & $\begin{array}{l}\text { Urteaga y } \\
\text { Alkaín } 2017 .\end{array}$ \\
\hline
\end{tabular}

Figura 3. Tabla comparativa del calzado analizado (Continuación).

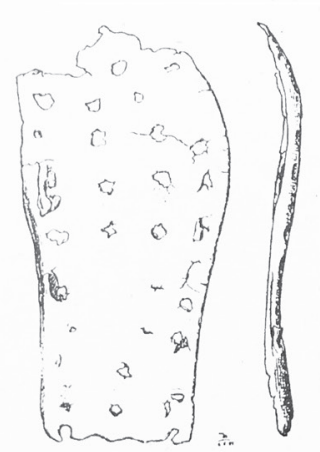

5

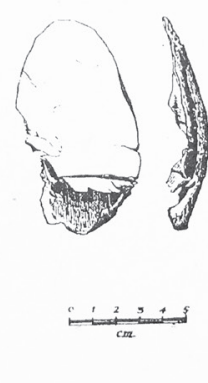

6

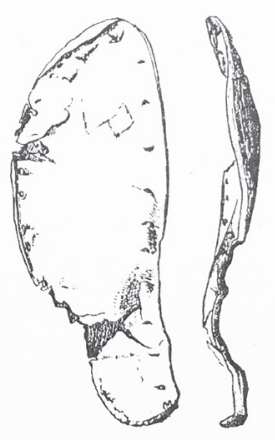

7

Figura 4. Suelas de calzado procedentes del interior de un pozo localizado en la ciudad romana de Iuliobriga (Campoo de Enmedio, Cantabria). Según el orden del catálogo, $n^{\circ}$ 5: suela claveteada; $n^{\circ}$ 6: suela de calzado infantil; $n^{\circ}$ 7: suela de zapato femenino. Fuente: García y Bellido (1957: fig. 55) (con modificaciones). 


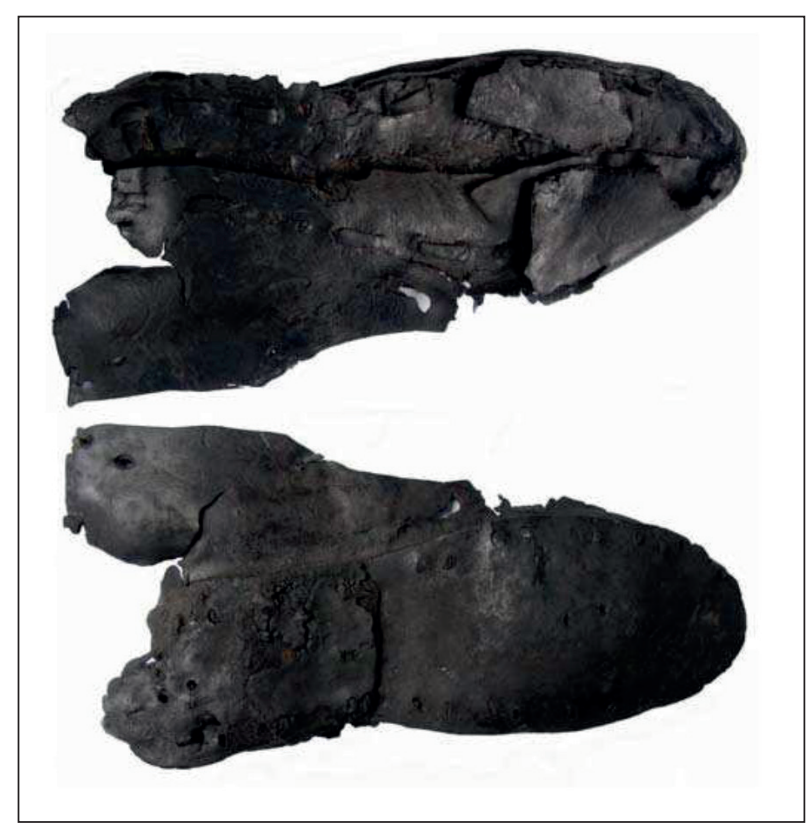

Figura 5. Vista delantera y trasera de un calzado cosido casi completo de las salinas romanas de O Areal (Vigo, Pontevedra); $n^{\circ} 9$. Fuente: Benavides (2010: 351).

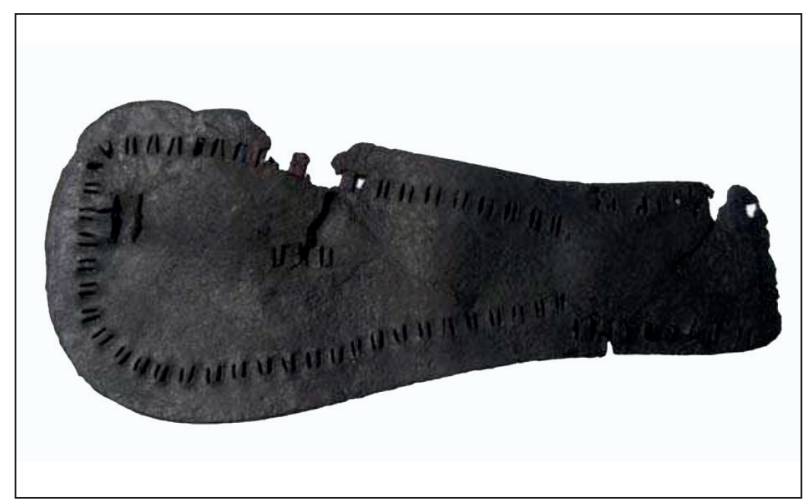

Figura 7. Sandalia o solea de las salinas romanas de O Areal (Vigo, Pontevedra); $n^{o}$ 11. Fuente: Benavides (2010: 352).

el periodo tardorrepublicano e inicios del siglo I d. C., la zona de marisma, dunas y playa sirven de fondeadero del Castro de Vigo. En época altoimperial (¿siglos I-II e inicios del III?) se construye y utiliza la salina aprovechando la marisma, playa y dunas. Es en este periodo cuando se construye además el barrio industrial salazonero (salinas y factorías de salazón). Durante el siglo III, se abandona la salina, inundándose su parte norte y colmatándose posteriormente por una duna y otros sedimentos continentales. Ya en época tardoantigua (siglos IV-VII), sobre la duna edafizada se dispone una necrópolis de incineración-inhumación y otras estructuras de difícil interpretación, aunque en el Sector Oriental se mantiene un uso portuario (Fernández, 2014: 75-113), habitacional, productivo además de ser espacio funerario, asociado a una posible iglesia.

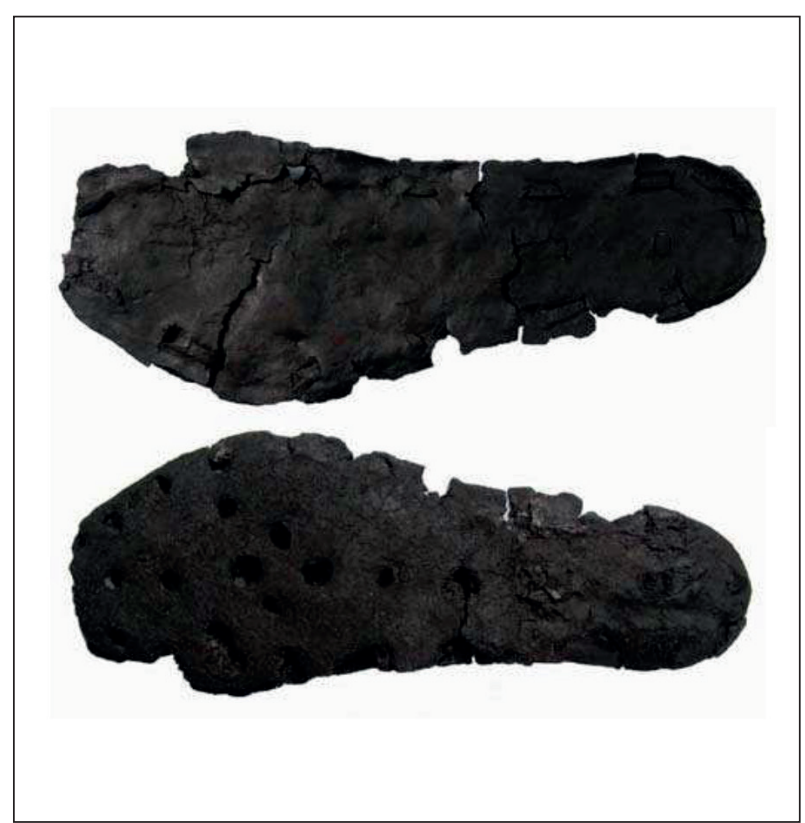

Figura 6. Vista delantera y trasera de un calzado claveteado de las salinas romanas de O Areal (Vigo, Pontevedra); $n^{\circ} 10$. Fuente: Benavides (2010: 351).

\subsection{Oiasso (Irún)}

También a una fase altoimperial (finales del siglo I d.C.-II d.C.) corresponden las diferentes suelas y restos de zapatos localizados en varias intervenciones arqueológicas realizadas en la antigua Oiasso en Irún (País Vasco) $\left(n^{\circ} 12-22\right)$ (fig. 8). En el complejo portuario de la calle Santiago (CSI 92), se documentaron en los años 1992 y 1993 estructuras portuarias correspondientes a un espigón (progressus) y un varadero para reparación de embarcaciones (navalia), además de cimentaciones de edificios y plataformas para el atraque de pequeñas embarcaciones. La excavación de este complejo portuario, fechado desde finales del siglo I d. C. hasta comienzos del siglo III (Urteaga, 2005), ha permitido localizar, al menos, cuatro cueros de calzado (Urteaga, 2017). Se trata de dos suelas de calzado infantil correspondientes al pie derecho $\left(\mathrm{n}^{\circ}\right.$ 19 y 21) y dos sandalias o soleae infantiles ( $\mathrm{n}^{\circ} 20$ y 22) pertenecientes a pie izquierdo y derecho que presentan bordes recortados con la forma de los dedos.

La intervención arqueológica realizada en Irún, a unos $40 \mathrm{~m}$ al oeste del complejo de calle Santiago, entre los años 1998 y 1999 puso al descubierto el complejo portuario de Tadeo Murgia (código de referencia: TMI 98). Se pudieron reconocer los restos de un muelle que presenta cuatro gradas (crepidine), fechado entre los años 70 y 120 d.C., con un uso continuado durante todo el siglo II d.C. (Urteaga, 2005; Urteaga y Arce, 2011). En esta intervención se localizaron, al menos, seis suelas de calzado claveteado ( $\mathrm{n}^{\mathrm{o}} 12$ y 14-22), en su mayoría correspondientes al pie derecho $\left(n^{\circ} 7,9-12,14,16\right.$ y 17$)$ y una suela de una sandalia infantil ( $\left.\mathrm{n}^{\circ} 13\right)$. El estado de conservación de las suelas de calzado claveteado ofrece la posibili- 
dad de determinar no sólo las diferentes capas que los componían, sino también el dibujo que conformaban las tachuelas, que nos permiten adscribirlos a los tipos ya identificados en las provincias septentrionales del Imperio romano (Van Driel Murray, 2001).

\subsection{Fábrica de Tabacos (Gijón)}

Los sondeos arqueológicos realizados en el interior de la antigua Fábrica de Tabacos de Gijón (Asturias) localizaron un pozo-depósito construido muy posiblemente entre finales del siglo III d.C. o durante el IV d.C. Los materiales recuperados en su interior y los análisis de muestras realizadas, tanto de objetos concretos, como de sedimentos orgánicos e inorgánicos, indican que este sirvió de vertedero entre finales del siglo $\mathrm{V}$ d.C. o inicios del VI d.C. (Fernández Ochoa et al., 2015: 165). Entre los materiales arrojados a su interior, que evidencian la pérdida de la actividad originaria del pozo-depósito durante la Antigüedad Tardía, nos interesa destacar el hallazgo de los restos de al menos cuatro suelas de cuero fechadas en este periodo $\left(\mathrm{n}^{\mathrm{o}} 1-4\right)$ (fig. 9) (Fernández Ochoa et al., 2015b: figs. 10 y 11 y lám. 5, nº 7). Seguramente corresponden todas las suelas documentadas a zapatos claveteados, aunque el estado de conservación nos permite confirmar este tipo solamente en los dos primeros $\left(n^{\circ} 1\right.$ y 2$)$.

\section{La CONSERVACión DEL CUERo Y EL CORDAJE}

Los fragmentos de calzado localizados en el norte peninsular proceden de diferentes contextos que presentan unas condiciones ambientales similares que han permitido la conservación de los materiales orgánicos perecederos. En todos los casos se trata de depósitos, contenedores o espacios dedicados al almacenaje o acumulación de agua. Los ejemplares de calzado de O Areal (Vigo) proceden de unas salinas romanas, los restos de Oiasso (Irún) provienen de un área anegada del antiguo complejo portuario de la ciudad, mientras que los materiales de Iuliobriga se localizaron en el interior de un pozo y los de Tabacalera (Gijón) en un enorme pozo-depósito de agua. En este último caso, los trabajos de conservación apropiados realizados desde el momento de su extracción

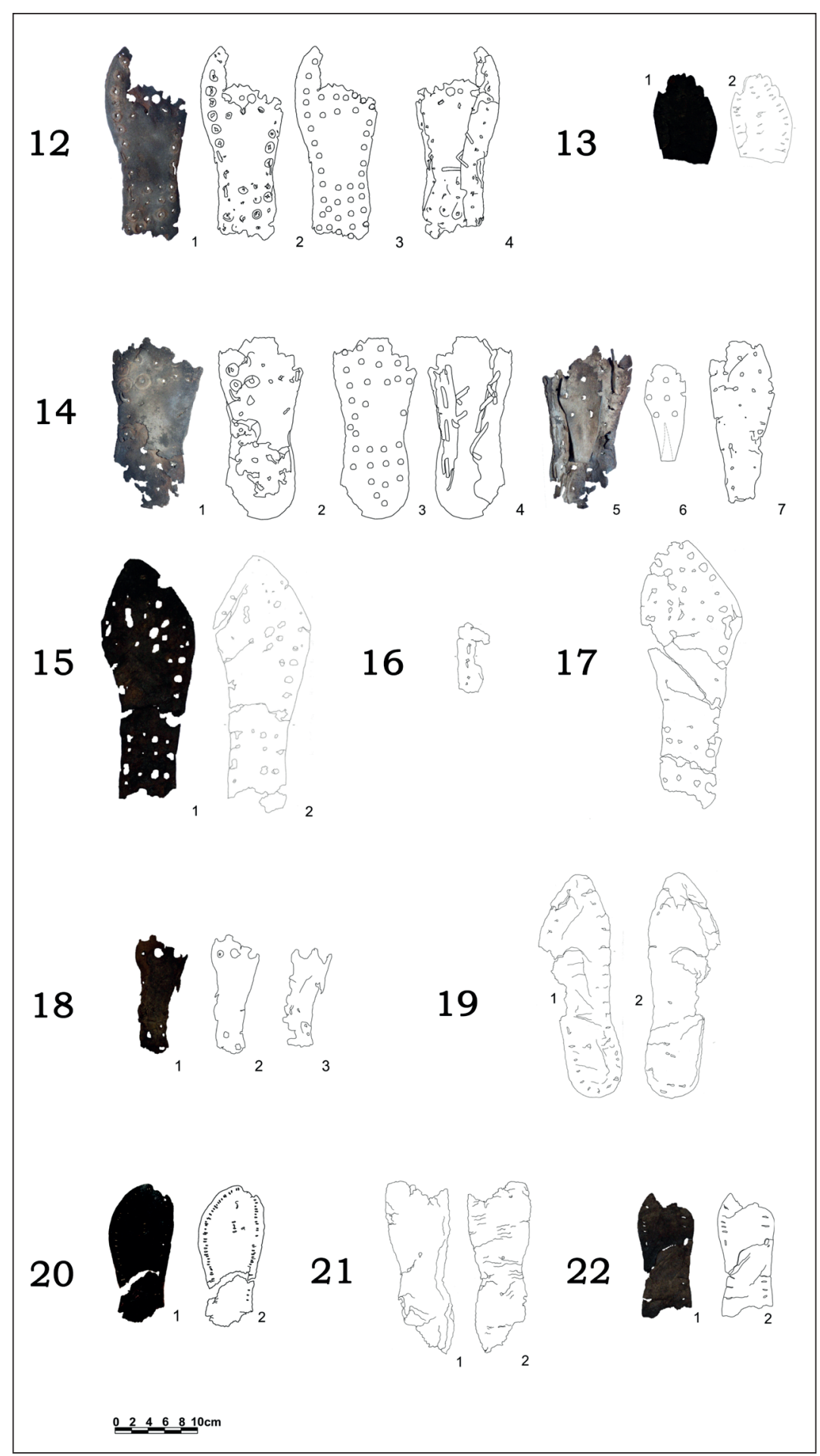

Figura 8. Suelas procedentes de la antigua Oiasso en Irún (País Vasco) con indicación del orden del catálogo. Fuente: Urteaga 2017 (con modificaciones).

hasta su posterior estudio y almacenaje o exposición al público $^{6}$, han permitido proteger y preservar las piezas

6 El calzado de la Fábrica de Tabacos de Gijón fue mostrado al público general durante los meses de agosto y diciembre de 2015 en la Exposición Un edificio, dos mil años de historia. La Fábrica de Tabacos de Gijón. 


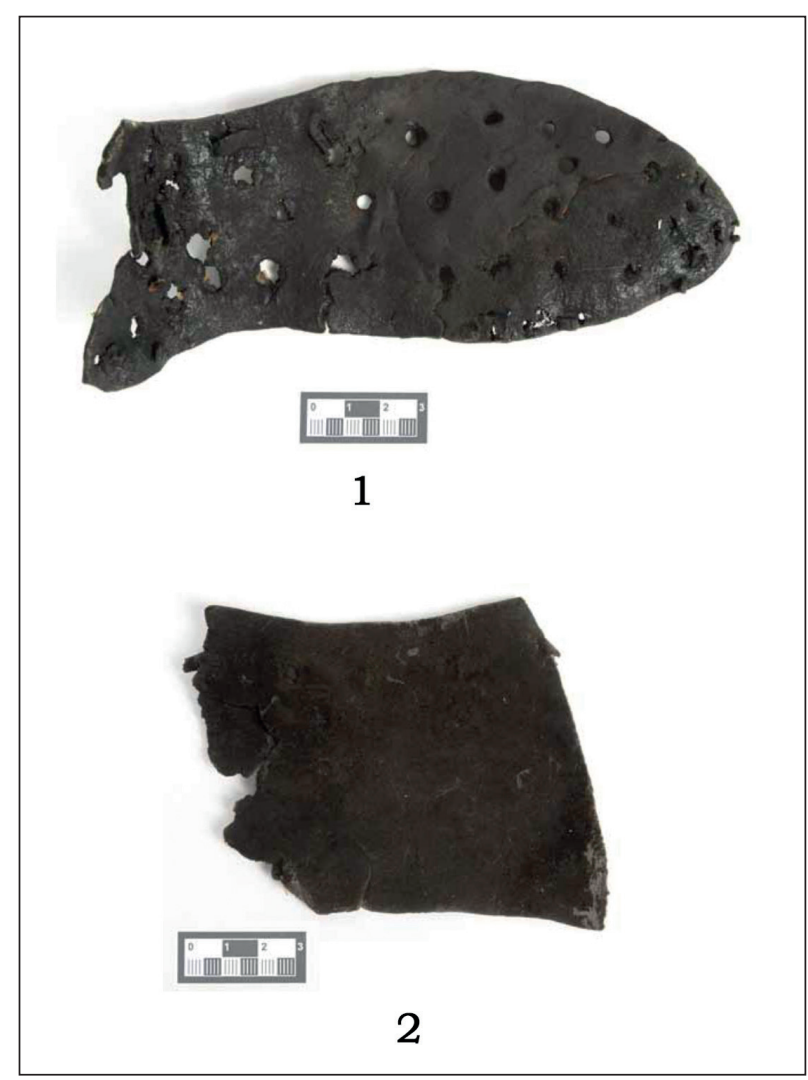

Figura 9. Suelas de zapato claveteado de la Fábrica de Tabacos (Gijón). Fuente: Fernández Ochoa et alii (2015: 138, fig. 10 y 11).

que de otro modo se hubieran perdido para siempre en el registro arqueológico. La aplicación de unas correctas medidas de prevención de los cambios bruscos de humedad relativa, así como de los procesos de rehidratación o de remoldeado con vapor de agua y de las humedades de condensación por el cambio rápido de un lugar frío a un lugar caliente, han permitido mantener la materia en un buen estado de conservación (González Álvarez, 2005: 86). Peor suerte corrieron los zapatos localizados en Iuliobriga que, como ya hemos comentado, se quemaron en un incendio fortuito en el lugar donde se depositaban.

La localización de estos materiales en ambiente húmedo o anegado es el factor que ha permitido su conservación, pero al mismo tiempo ha provocado importantes cambios del estado del material y problemas en su conservación debido a la degradación en el proceso de frágil equilibrio al que llegan con el medio que les rodea desde el momento de su deposición. El agua es, en este sentido, un factor importante a tener en cuenta como principal agente tanto del deterioro de las estructuras fibrilares del cuero, como de su conservación en ambientes saturados de humedad.

El principal cambio que evidenciamos en el calzado es la transformación del material de composición del cuero y el cordaje, que muestran unas alteraciones físico-químicas, mecánicas y biológicas, que se manifiestan principalmente con el cambio de la forma, la coloración y el peso. Gene- ralmente, las piezas de cuero aparecen muy debilitadas, oscurecidas y presentan numerosas fendas y fisuras. Algunos ejemplares como las suelas y el calzado localizado en O Areal (Vigo) (nº-11) parecen presentar, a simple vista, un buen estado de conservación, pero en estos casos, hay que tener en cuenta que la desnaturalización del colágeno en los procesos de deterioro de los objetos de cuero no es un fenómeno observable, sino que se debe medir a través del parámetro "temperatura de contracción", es decir, temperatura a la que se produce la desnaturalización del colágeno cuando el cuero es progresivamente calentado en agua destilada (González Álvarez, 2005: 82). De hecho, el estudio de este ejemplar determinó que no sólo sufrió un gran deterioro a nivel fibrilar, sino que además estuvo expuesto a otros agentes de deterioro como los residuos industriales del garaje que durante varias décadas ocupó el solar donde se localizaron. A pesar de encontrarse en las salinas, en un terreno ganado al mar en la actualidad, las sales solubles (cloruros y nitratos) del agua que rodeaba a las piezas era bajo, mientras que las sales menos solubles (sulfatos) eran muy elevadas. De hecho, según la información aportada por Benavides (2010: 352), también presentaban un olor intenso a sulfhídrico, aunque en este caso podía deberse a los residuos o degradación bacteriana de la materia orgánica tan presente en el yacimiento o al posible uso de alumbre para el curtido de la piel. En los ejemplares localizados en Oiasso (Irún) la parte exterior de la pala o parte superior del calzado presentaban un mal estado de conservación por el contacto con el medio húmedo circundante.

En cuanto al cordaje, los escasos restos conservados y los agujeros presentes en la suela $\mathrm{n}^{\circ} 1$ de la Fábrica de Tabacos de Gijón, nos permitió determinar el tipo de cosido que es el más simple según el modelo de Göpfrich (Göpfrich et al., 1986: 11-12, fig. 4), como ya indicamos dos de los firmantes de este trabajo en la publicación del material (Fernández Ochoa et al., 2015: 138) (fig. 10). Otras dos suelas del calzado claveteado de Oiasso (Irún) presentaban evidencias del cosido. La suela $\mathrm{n}^{\circ} 14$, aunque no conservaba la parte exterior al ser la más fina y delicada, aún contaba con las cintas de cuero mediante la cual se fijaba a la suela. También se puede observar un segundo cordón de cuero que servía para unir los dos extremos de la pala en zig-zag. Este es el mismo cosido que presentaba el cuero del zapato $\mathrm{n}^{\mathrm{o}} 12 \mathrm{del}$ mismo yacimiento. Igualmente conservaban marcas de cosido las sandalias o soleae de Irún, tanto la documentada en el complejo portuario de Tadeo Murgia ( $\left.\mathrm{n}^{\circ} 13\right)$ como las procedentes de las estructuras de la calle Santiago ( $\mathrm{n}^{\circ} 20$ y 22). La primera $\left(\mathrm{n}^{\circ} 13\right)$ presenta un total de 20 marcas de cosido de aproximadamente $3 \mathrm{~mm}$ de anchura, agrupándose los orificios en parejas. En la zona central delantera además se advierten tres marcas de cosido para fijar las cintas de sujeción del pie. La suela $\mathrm{n}^{\mathrm{o}} 20$ conserva 61 marcas de cosido a unos $8 \mathrm{~mm}$ del borde, de aproximadamente 3 $\mathrm{mm}$ de anchura. En la zona central delantera cuenta con 4 orificios de cosido de 3-4 mm de anchura, para fijar la cinta de sujeción del pie. El mismo tipo de huella de cosi- 
do se localiza a la altura del enfranque. El perímetro del calzado $n^{\circ} 22$ presenta un total de 11 marcas de cosido de la misma anchura. También se localizó en Irún una suela de calzado con orificios de cosido en el borde ( $\left.n^{\circ} 19\right)$, en este caso, correspondientes a un zapato cerrado. La solea de las salinas romanas de O Areal (Vigo) contaba con marcas de cosido en la zona perimetral y en la parte central para acoger el encintado que sujetaba el pie.

\section{Estudio analítico del Calzado de LA HISPANIA SEPTENTRIONAL EN ÉPOCA ROMANA Y TARDOANTIGUA}

Los testimonios de calzado documentados hasta la fecha en esta región de Hispania durante el periodo romano y tardoantiguo corresponden a diferentes modelos que podríamos englobar en tres tipos: calzado claveteado, calzado cerrado sin suela claveteada y sandalias o soleae.

El calzado claveteado o con tachuelas es el que más atención ha recibido por parte de los especialistas (fig. 11). Las tachuelas se colocaban en diferentes tipos de calzado, siendo más habitual en las provincias del norte del Imperio que en las zonas mediterráneas y orientales, debido a las condiciones climáticas, pues su uso ofrece ventajas para caminar en terrenos blandos y, en cierta medida, disminuye el desgaste del zapato (Leguilloux, 2004: 111). La disposición de las tachuelas y la forma de las suelas son argumentos utilizados para fechar estos materiales.

En la Península Ibérica contamos con buenos ejemplares que nos aportan datos importantes sobre la evolución del calzado desde el periodo clásico al tardoantiguo. De las salinas romanas de O Areal (Vigo) procede una suela claveteada, que

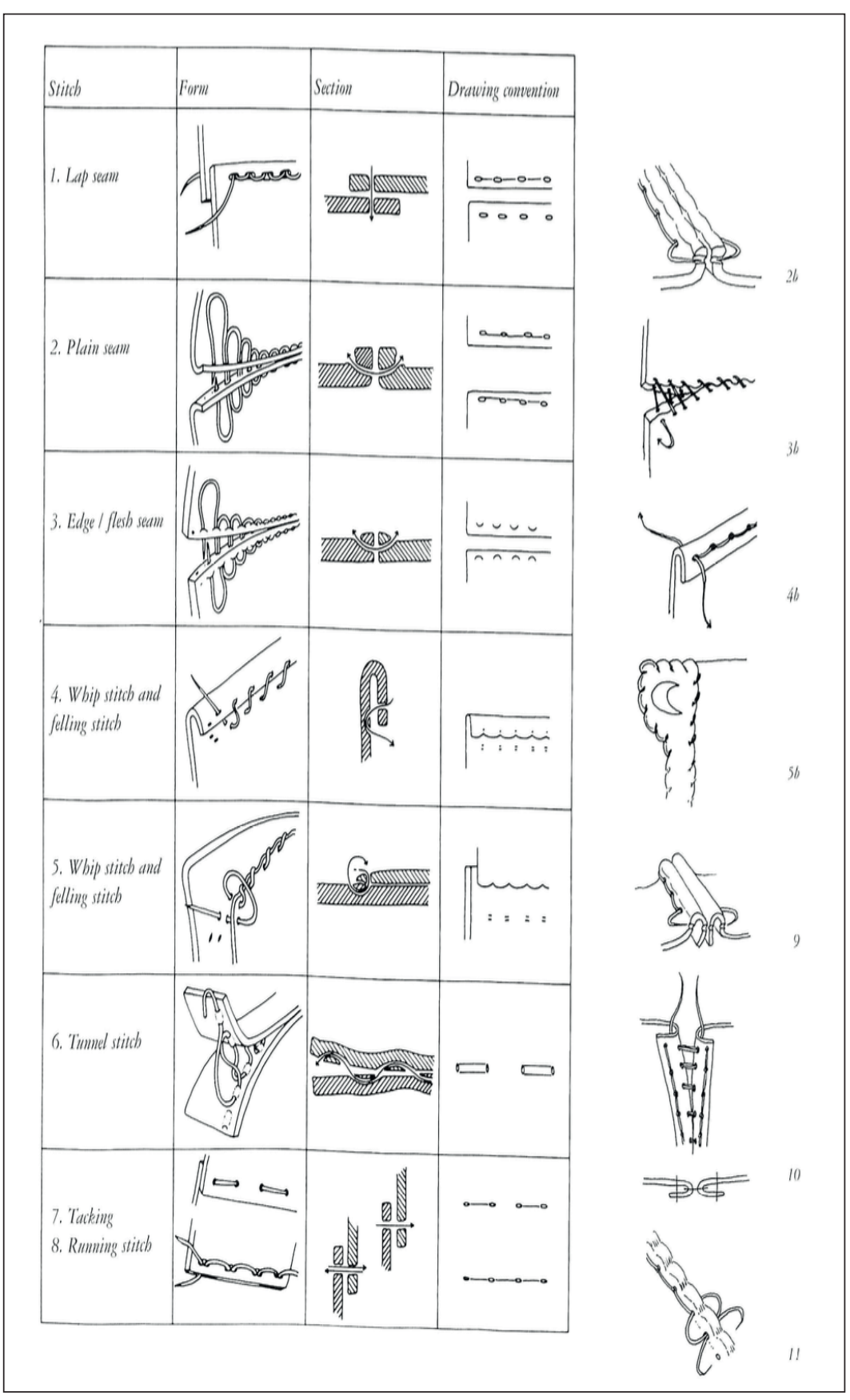

Figura 10. Tipos de cosido de época romana. Fuente: Van Driel-Murray (2001: fig. 13 y 14). cuenta con una fila de tachuelas que recorre todo el calzado, correspondiendo al tipo 1a de Van Driel-Murray (2001: 351, fig. 21), que en contextos del norte de Europa, se fechan a finales del siglo II d.C., coincidente con la datación de las salinas. De los diferentes ejemplares documentados en las excavaciones del complejo portuario de Tadeo Murgia en Oiasso (Irún), al menos tres ( $n^{\circ} 12,14$ y 18$)$ parecen corresponder a zapatos cerrados claveteados, que bien podrían corresponder a socci (zapatos cerrados), campagi (calzados de empeine abierto) o calcei (calzados con cintas), mientras que otros tres ejemplares $\left(n^{\circ} 15,16\right.$ y 17) bien podrían ser de este tipo o corresponder a caligae (Urteaga y Alkaín, 2017). La disposición de las tachuelas en las piezas n ${ }^{\circ} 12,14,15$

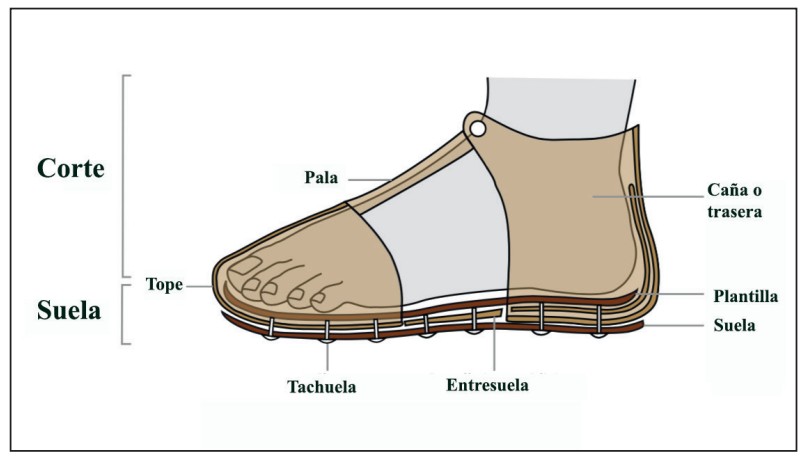

Figura 11. Partes del calzado claveteado. Imagen: realizada a partir de Le Forestier (2013). 


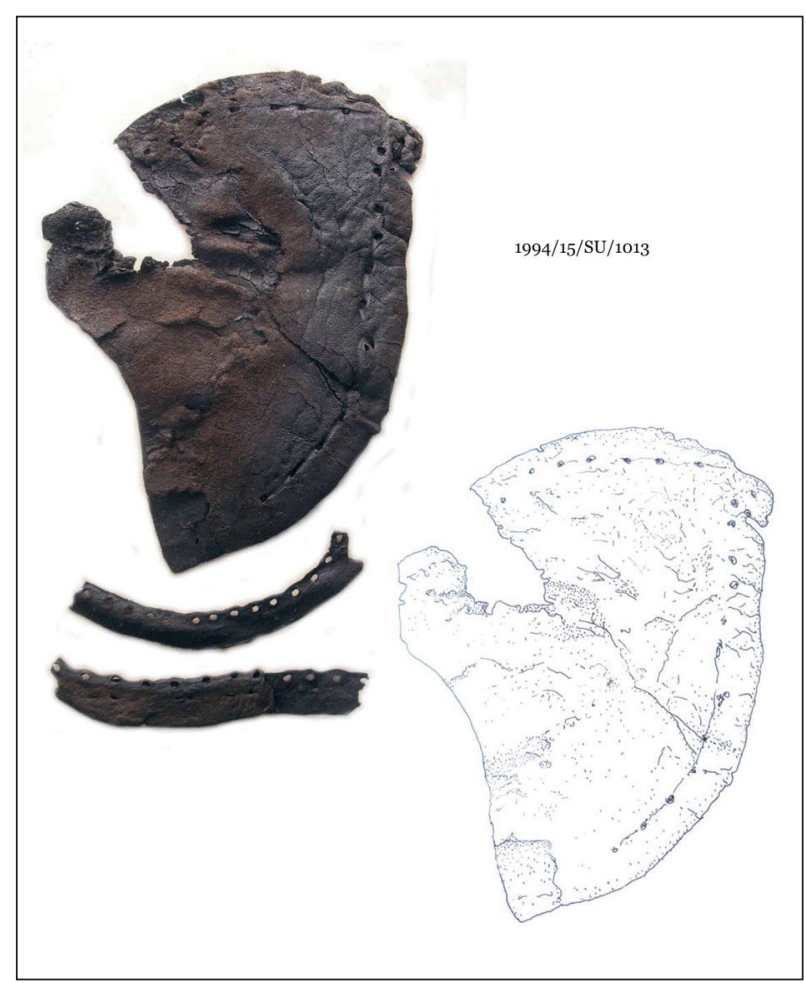

Figura 12. Suela medieval procedente de León con marcas de cosido. Imagen: Ángel Morillo.

y 17 con una sola línea que rodea el perímetro de la suela y su concentración tanto en el tacón como en la planta, quedando libre el enfranque, nos permite encuadrarlo en el tipo 1 de Van Driel-Murray (2001: 351, fig. 21) que ha sido fechado en las regiones septentrionales del Imperio romano a finales del siglo II d.C. Esta cronología concuerda bien con la de los materiales hallados en el yacimiento que se datan a partir del año 70 d.C. y durante el siglo II d.C. También la forma de las suelas encajan perfectamente con la cronología propuesta, pues la forma recta de las piezas $\mathrm{n}^{\mathrm{o}} 12$ y 14 suelen datarse entre finales del siglo I d.C. y comienzos del II d.C., mientras que la forma del calzado $\mathrm{n}^{\circ} 15$ ligeramente apuntado y con una forma más sinuosa se fecha en la segunda mitad del siglo II d.C. en contextos del norte de Europa (Van Driel-Murray, 2001: 350, fig. 20), coincidiendo de nuevo con la cronología del yacimiento. En estos últimos ejemplares nos encontramos con los materiales quizás usados en el momento final de uso del complejo portuario.

En relación con la producción de calzado claveteado en Irún, cabe destacar el descubrimiento en 1997 de varios utensilios de un herrero que producía tachuelas en la calle Beraketa, en un entorno urbano situado a unos $50 \mathrm{~m}$ de distancia de las termas del Juncal, en la zona septentrional de la aglomeración de Oiasso. La cronología del material enterrado en la primera mitad del siglo I d. C. (Urteaga, 2015: 103, 2017), no nos permite en cambio relacionarlo con el material de cuero localizado en el complejo portuario de Tadeo Murgia, pero conviene señalar ya la tradición manufacturera de calzado en esta población.

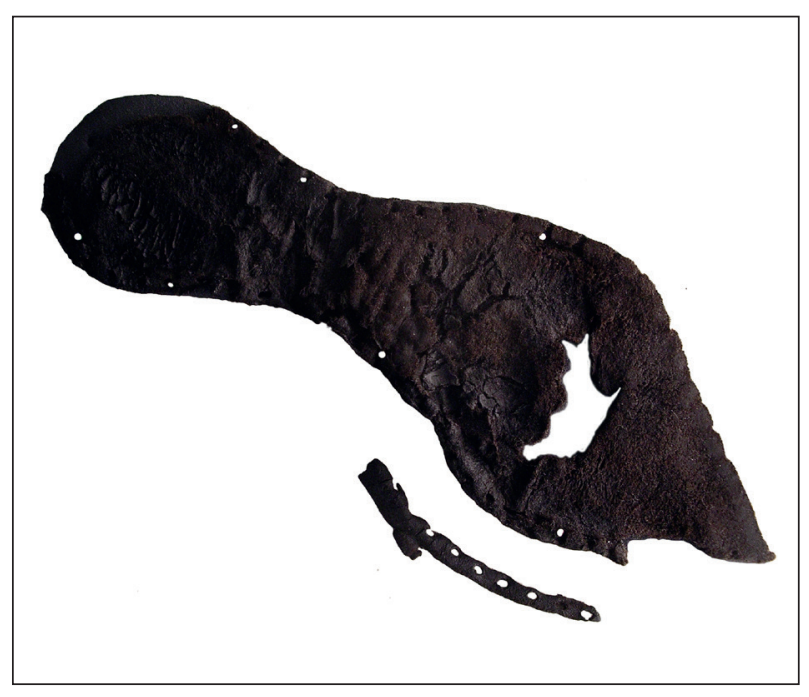

Figura 13. Suela de calzado medieval apuntado procedente de León. Imagen: Ángel Morillo.

Uno de los ejemplares de calzado procedentes de Iuliobriga (Cantabria) ( $\left.\mathrm{n}^{\circ} 5\right)$ también presenta tachuelas. Tanto la forma recta de la suela como la disposición de las tachuelas con una sola línea que bordea el perímetro y con una mayor concentración en el tacón y la planta, nos permiten de nuevo fecharlo en el siglo II d.C., cronología que coindice perfectamente con el material localizado en el interior del pozo (García y Bellido, 1957: 149-150).

La suela de cuero claveteada procedente de la Fábrica de Tabacos de Gijón ( $\left.\mathrm{n}^{\circ} 1\right)$, bastante completa y deformada, se ha podido fechar entre el final del siglo VI y las postrimerías del siglo VII. El interior de la suela estaba claveteada con fuertes tachuelas, alineadas en tres filas de nueve cada una. La forma del calzado es apuntada y presenta en la parte más sobresaliente un refuerzo con cuatro tachuelas dispuestas en forma de cruz. La zona del talón está asegurada con más láminas de cuero. El empleo de tachuelas de la primera suela es característico del calzado de época romana y su mayor uso lo diferencia del de otras épocas. Los ejemplares de calzado medieval mejor conservados presentan muchas analogías con el de época romana, pues el tipo de material utilizado es semejante, pero la forma es más apuntada y la técnica de fabricación difiere en cuanto al cordaje (menos oculto en el calzado romano que es usado como un efecto decorativo adicional) y el menor empleo de tachuelas. Una buena muestra de ello es el calzado localizado en León, también al norte de la Península Ibérica (figs. 12 y 13). Estudios tan detallados como el análisis del cuero medieval de York ilustran sobre la ausencia de tachuelas en las suelas aparecidas (Mould et al., 2003: 3268-3353); otras investigaciones llegan a las mismas conclusiones (Hald, 1972). Generalmente la pieza de cuero superior era cosida a los bordes de la suela, como se ilustra en los ejemplares medievales leoneses a los que nos acabamos de referir.

Así pues, este ejemplar de Gijón se halla a medio camino entre los modelos antiguos y los medievales. Por un 
lado, el uso de las tachuelas y su disposición en el calzado es más propio de tipos romanos; de hecho, se asemeja al modelo 3a, propuesto por Van Driel-Murray (2001: 351) en su estudio sobre el calzado romano de las provincias septentrionales del Imperio, pues conserva los agujeros de una alineación central, una junto a los márgenes de la suela y otra paralela a esta, sin clavos en la zona del puente o arco de la parte interior de la planta. En las regiones del norte del Imperio, este modelo es particularmente frecuente a finales del siglo I d.C. y en el siglo II d.C. Algunos ejemplares presentan incluso una disposición muy similar a la del calzado aparecido en el depósito de la fábrica gijonesa (Göpfrich et al., 1986: fig. 44.96). A partir del siglo II d.C., comienzan a ser cada vez más ligeros. En el primer tercio del siglo III d.C. los diseños se enriquecen y tanto en este siglo como durante el IV d.C. son más frecuentes las figuraciones con clavos en forma de $\mathrm{S}$, de rombos, círculos, cruces gamadas, tridentes, etc. (Van Driel-Murray, 2001: 351). Sin embargo, la forma apuntada de la suela y el refuerzo del tacón es propio de calzados de época posterior (Le Forestier 2014, 2015, 2016). Así pues, este modelo con características propias del calzado romano (tachuelas) y medieval (forma apuntada y refuerzos del tacón) se podría explicar por la cronología tardoantigua de la pieza (fig. 14). A diferencia de lo que evidencia el registro funerario donde se abandona el enterramiento de difuntos con calzado claveteado a finales del siglo $\mathrm{V} \mathrm{d}$. C., quizás en relación a un cambio en el ritual (Vigil-Escalera, 2015: 210), los ejemplares de Gijón vienen a confirmar que aún en el periodo tardoantiguo se mantiene el uso de las tachuelas.

Junto a estas claveteadas, se localizó un gran número de suelas que no presentan agujeros donde se colocaban las tachuelas. Debieron corresponder a zapatos cerrados de los que desconocemos la tipología y denominación concreta ante la ausencia de la parte superior y cierre de cuero. La forma de las suelas son muy diferentes de las correspondientes a sandalias o soleae, siendo estas mucho más anchas e incluso con la forma de los dedos marcados. El ejemplar más completo conservado procede de las salinas de O Areal (Vigo), posiblemente correspondiente a una carbatina, zapatos de pieza simple, acordonados, fabricados con un único pedazo de cuero y detalles agregados arriba de este.

De Iuliobriga se ha testimoniado un calzado infantil $\left(n^{\circ} 6\right)$ y otro posiblemente femenino $\left(n^{\circ} 7\right)$, dadas las reducidas dimensiones con respecto a la otra suela claveteada documentada en el pozo. También corresponden a calzado cosido infantil dos ejemplares procedentes de Oiasso ( $\mathrm{n}^{\mathrm{o}} 19$ y 21 ), ambos correspondientes al pie derecho. Uno de ellos está compuesto por tres piezas de cuero, unidas mediante cosido, como demuestran los orificios que se pueden observar aún en los bordes.

El último tipo documentado corresponde a las suelas de sandalias o soleae. El ejemplar mejor conservado se localizó en las salinas romanas de O Areal (Vigo). Presenta los restos de cosido perimetral que nos indica que la sandalia estaba fabricada con varias capas de cuero $\left(n^{\circ} 11\right)$. De igual modo, presenta las marcas de cosido de las correas o cintas que permitían sujetar el pie. Tres ejemplares más $\left(n^{\circ} 13,20\right.$ y 22) se localizaron en la antigua Oiasso (Irún), en este caso, correspondiente a sandalias infantiles. Cabe destacar el recorte de la parte delantera de la suela con la forma de tres dedos en las dos primeras y de un dedo en la última. Al igual que en la pieza gallega, presentan, en todo el perímetro, marcas de cosido y en la zona central delantera, al menos, tres marcas de cosido más para fijar las cintas de sujeción del pie. El recorte con la forma anatómica de los dedos y su reducido tamaño permite fecharlas entre finales del siglo I a. C. y mediados del II d. C. (Leguilloux, 2004: 131; Urteaga, 2017). A partir de esta última fecha, además su uso se extendió al ámbito masculino, introduciéndose cambios en la tipología de las suelas (Van Driel, 2001: 355).

Respecto al contexto, nos parece que el calzado clásico y tardoantiguo que ha llegado hasta nuestros días es producto de la casualidad en el caso de las salinas romanas de O Areal y de los complejos portuarios de Oiasso, pues posiblemente los cueros y suelas localizados corresponden al calzado de los trabajadores de dichos espacios productivos y comerciales. La tipología de los diferentes ejemplares coinciden plenamente con las cronologías que se han propuesto para ambas instalaciones a partir del material asociado, como hemos indicado anteriormente. En este sentido, cabe destacar el calzado de finales del siglo II d.C., de Irún que correspondería al último momento de uso de las estructuras portuarias de Tadeo Murgia. Este material de cuero está muy presente en numerosos yacimientos de época romana del norte de Europa, con condiciones de humedad muy similares a las de los contextos hispanos, completamente anegados, como en las riberas de los ríos, en Maguncia (Göpfrich et al., 1986), Colonia (Schleiermacher, 1982), Londres (Rhodes, 1980), Zwammerdam (Van Driel-Murray, 1977), Pommeroeul (De Boe y Hubert, 1977), Vechten, Woerden, Velsen y en el vicus de Valkenburg (Groenman-Van Waateringe, 1967), así como en rellenos y niveles de fosas encharcadas, como en Nimega (Groenman-Van Waateringe, 1967), Bar Hill (Robertson et al., 1975) y Vindolanda (Van Driel-Murray, 2001b), y también en vertederos de basura que han sellado niveles con un alto porcentaje de humedad, como en Vindonissa (Gansser-Burckhardt, 1942) y Bonn (Van Driel-Murray y Gechter, 1983).

Menos dudas ofrece el material procedente del pozo de Iuliobriga (Cantabria) y de la Fábrica de Tabacos (Gijón) que muy posiblemente fueron arrojados al interior de dichas estructuras negativas cuando estas ya no se hallaban en uso y eran empleadas como simples vertederos. El ambiente cerrado y húmedo ha preservado dichos objetos de cuero curtido en buen estado de conservación. Esta ubicación es muy común en diversos yacimientos de época romana, pues tenemos constancia del hallazgo de calzado en el interior de pozos y depósitos de agua en los yacimientos de Salzburgo y Zugmantel (Van Driel-Murray, 1965), Welzheim (Van Driel-Murray, 1999), Newstead (Curle, 


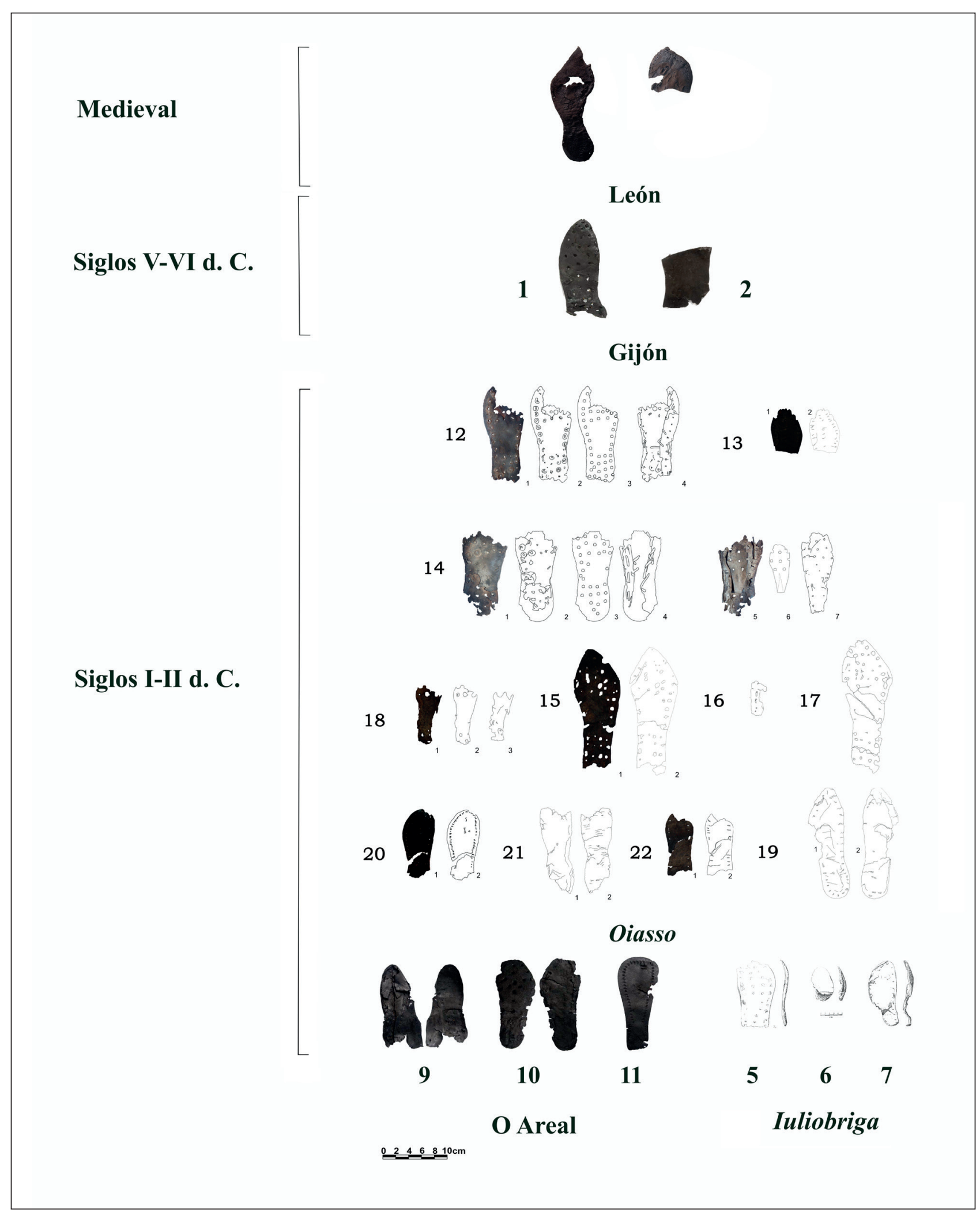

Figura 14. Evolución del calzado romano, tardoantiguo y medieval en el norte peninsular.

1911) y Ambrussum (Fiches, 2012: 256-260). Los objetos pudieron ser arrojados como materiales de desecho, aunque en otros casos sabemos de prácticas rituales asociadas con ofrendas como el calzado depositado en el interior del pozo de Matagne-le-Petit (De Boe, 1982: fig. 19) y de Erps-Kwerps en Bélgica (Lentacker et al., 1992: fig. 7).

Para finalizar, nos interesa destacar que un aspecto que permanece oculto en el registro arqueológico hace refe- 
rencia al oficio de los zapateros, como su condición social y su relación con las fullonicae y el trabajo del encurtido y el tintado. Esta problemática que es común a otras regiones del Imperio romano, seguramente se irá desvelando a medida que se inicien estudios de conjunto sobre las áreas de producción y trabajo del cuero en relación con los asentamientos donde se han localizado estos materiales, un trabajo que esperamos que en el futuro pueda emprenderse de una forma unitaria y coordinada.

\section{Bibliografía}

Abásolo, J.A.; Cortes, J. y Pérez Rodríguez, F. (1997): La necrópolis Norte de La Olmeda (Pedrosa de la Vega, Palencia). Palencia.

Alfaro Giner, C. (1984): Tejido y cestería en la Península ibérica desde la Prehistoria hasta la Romanización. Madrid.

Azkarate, A. (1999): "Necrópolis tardoantigua de Aldaieta (Nanclares de Gamboa, Álava). Volumen I. Memoria de la excavación en inventario de los hallazgos". Memorias de yacimientos alaveses, 6. Vitoria-Gasteiz.

Benavides García, R. (2010): “Conservación de materiais orgánicos empapados das salinas romanas de Rosalía de Castro II, Vigo (Pontevedra)". Actuacións Arqueolóxicas Ano 2008. La Coruña: 351-353.

Caballero Zoreda, L. (1974): La necrópolis tardorromana de Fuentespreadas (Zamora). Un asentamiento en el valle del Duero. Excavaciones Arqueológicas en España 80. Madrid.

Carlsson-Brandt Fontán, E. (2011): "El material constructivo latericio en el campamento romano de Cidadela". Gallaecia, 30: 167-180.

Castro Carrera, J.C.; Prieto Robles, S.; Sartal Lorenzo, M.; Acuña Piñeiro, A.; Iglesias Darriba, M.J.; Rodríguez Sáinz, E. y Fernández Fernández, A. (2017-en prensa): "La salina romana de evaporación solar de O Areal-Vigo (Galicia, España): un ejemplo de arquitectura "efímera" conservada”. En A. Morillo, M. Hermanns y J. Salido (eds.): Arqueología "efimera". Productos y materiales perecederos en el registro arqueológico de época romana. Madrid.

Chabal, L. y Feugère, M. (2005): "Le mobilier organique des puits antiques et autres contextes humides de Lattara". Lattara, 18: 137-188.

Chabal, L.; Fiches, J.-L.; Mathieu, V. y Vincent-Falquet, A. (2012): "Poutres, appareillages et mobiliers en bois". En J.-L. Fiches (ed.): Quatre puits de l'agglomération routière gallo-romaine d'Ambrussum (Villetelle, Hérault). Montpellier: 65-127.

Charlesworth, D. y Thornton, J.H. (1973): "Leather found in Mediobogdum, the Roman fort of Hardknott". Britannia, 4: 141-112. DOI: https://doi.org/10.2307/525862

Curle, J. (1911): A Roman frontier post and its people: the Fort of Newstead in the parish of Melrose. Glasgow.

De Boe, G. (1982): Le sanctuaire Gallo-Romain dans la plaine de Bieure à Matagne-le-Petite. Archaeologia Belgica 251. Bruselas.
De Boe, G. y Hubert, F. (1977): "Une installation portuaire d'epoque romaine a Pommeroeul". Archaelogia Belgica, 192: 1-57.

Fernández Ochoa, C.; Gil Sendino, F. y Salido, J. (2015): "Estudio de los materiales arqueológicos". En C. Fernández Ochoa, A. Orejas, P. García y F. Gil Sendino (eds.): La Fábrica de Tabacos de Gijón. Arqueología e Historia de un espacio milenario. Gijón: 126-157.

Fernández Ochoa, C.; Orejas, A. y Gil Sendino, F. (2015b): "Arquitectura y función del pozo-depósito de Tabacalera”. En C. Fernández Ochoa, A. Orejas, P. García y F. Gil Sendino (eds.): La Fábrica de Tabacos de Gijón. Arqueología e Historia de un espacio milenario. Gijón: 158-181

Fernández, A. (2014): El comercio tardoantiguo (ss. IV-VII) en el Noroeste peninsular a través del registro cerámico de la Ría de Vigo. Roman and Kate Antique Medirerranean Pottery 5. Oxford.

Fiches, J.-L. (2012): “Cuirs, sandales cloutées et cordes". En J.-L. Fiches Quatre puits de l'agglomération routière gallo-romaine d'Ambrussum (Villetelle, Hérault). Montpellier: 256-260.

Fremersdorf, F. (1926): "Ein Fund römischer Ledersachen in Köln”. Germania, 10: 44-56.

Galindo, L. y Sánchez, V.M. (2005): “La necrópolis tardoantigua de 'Gerona 4' en Móstoles". Huellas. Actuaciones de la Comunidad de Madrid en el patrimonio histórico. Madrid: 71-77.

Gansser-Burckhardt, A. (1942): Das Leder und seine Verarbeitung im römischen Legionslager Vindonissa, Veröffentlichungen der Gesellschaft pro Vindonissa 1. Basel.

García y Bellido, A. (1956): "Excavaciones en Iuliobriga y exploraciones en Cantabria. II relación. Campañas de 1953 a 1956". Archivo Español de Arqueología, 29: 156-167.

Gea García, A. y Dávila Buitrón, C. (2017-en prensa): "Los materiales orgánicos en el contexto arqueológico: problemas de conservación y protocolo de actuación”. En A. Morillo, M. Hermanns y J. Salido (eds.): Arqueología "efimera". Productos y materiales perecederos en el registro arqueológico de época romana. Madrid.

Goldman, N. (1994): "Roman footwear". En J.L. Sebesta y L. Bonfante (eds.): The world of Roman costume: 101-133.

González Álvarez, G.M. (1996): "Resistencia a la rotura y colapso fibrilar en objetos de cuero". XI Congreso de Conservación y Restauración de Bienes Culturales. Castellón: 257-266.

González Álvarez, G.M. (2005): "Recientes avances en conservación de objetos de cuero". Museos.es: Revista de la Subdirección General de Museos Estatales, 1: 80-87.

Göfrich, J.; Rupprecht, G. y Baatz, D. (1986): "Römische Lederfunde aus Mainz”. Saalburg Jahrbuch, 42: 5-67.

Gräf, J. (2009): "Schuhe aus dem Moor. Schuhfunde im Landesmuseum für Natur und Mensch Oldenburg". Museumsjournal Natur und Mensch, 4: 53-70. 
Groenman-Van Waateringe, W. (1967): Romeins lederwerk uit Valkenburg Z: H. Nederlandse Oudheden 2. Groningen.

Gutiérrez Cuenca, E. y Hierro Gárate, J.A. (2010): “Instrumentos relacionados con la actividad textil de época tardoantigua y altomedieval en Cantabria". Munibe, 61: 261-288.

Hald, M. (1972): Primitive shoes. An archaeological-ethnological study based upon shoe finds from the Jutland Peninsula, Nationalmuseets Skrifter. Arkaeologisk-Historisk Raekke 13. Copenhage.

Larsen, R. (1996): "Deterioration and Conservation of vegetable tanned leathers: The Environment Leather Project". Leather Conservation News, 12 (1): 1-8.

Le Forestier, C. (2013): "Les chaussures gallo-romaines en Île-de-France: approche archéo-anthropologique". Revue archéologique d'Île-de-France, 6: 161-184.

Le Forestier, C. (dir.) (2014): Archéologie des nécropoles mérovingiennes en Île-de-France Rapport d'activité 2015. Programme collectif de recherche. Îlede-France.

Le Forestier, C. (dir.) (2015): Archéologie des nécropoles mérovingiennes en Île-de-France Rapport d'activité 2015. Programme collectif de recherche. Îlede-France.

Le Forestier, C. (dir.) (2016): Archéologie des nécropoles mérovingiennes en Île-de-France Rapport d'activité 2015. Programme collectif de recherche. Île-de-France.

Leguilloux, M. (2004): Le cuir et la pelleterie à l'époque romaine. Paris.

Lentacker, A.; Bakels, C.C.; Verbeeck, M. y Desender, K. (1992): "The archaeology, fauna and flora of a Roman well at Erps-Kwerps (Brabant, Belgium)". Helinium, 32: 110-131.

Macconnoran, P. (1986): "Footwear". En L. Miller, J. Schofield y M. Rhodes (eds.): The Roman Quay at St Magnus House, London. Excavations at New Fresh Wharf, Lower Thames Street, London 1974-78. Londres: 218-226.

MacGregor, A. (1978): Roman finds from Skeldergate and Bishophill. The Archaeology of York 17 (2). Londres.

Maluquer de Motes, J. (1968): "Excavaciones arqueológicas en el castro de "Las Merchanas" (Lumbrales, Salamanca)". Pyrenae, 4: 101-128.

Merrifield, R. (1987): The Archaeology of Ritual and Magic. Londres.

Morillo Cerdán, A. y Salido Domínguez, J. (2013): “Marcas militares sobre producciones latericias en Hispania. Nuevas consideraciones sobre su origen y difusión". Gerión, 31: 287-329.

Morillo Cerdán, A.; Hermanns, M. y Salido Domínguez, J. (2018-en prensa): Arqueología "Efimera". Productos y materiales perecederos en el registro arqueológico de época romana.

Morillo Cerdán, A.; Rodríguez Martín, G.; Durán Cabello, R. y Martín Hernández, E. (2010): El Puente y calzada de Becilla de Valderaduey (Valladolid). Análisis arqueológico y arquitectónico. León.
Mould, Q. (1997): "Leather”. En T. Wilmott, L. Hird, K. Izard y J. Summerfield (eds.): Birdoswald. Excavations of a Roman fort on Hadrian's Wall and it successor settlements: 1987-92. English Heritage, Archaeological Report 14. Londres: 326-341.

Mould, Q.; Carlisle, I. y Cameron, E. (2003): Leather and Leatherworking in Anglo-Scandinavian and Medieval York. Craft, Industry and Everyday Life: The Small Finds. York.

Muñoz Carballo, G. (1994): "Excavaciones en el castro de la Dehesa de la Oliva (Patones, Madrid)". Boletín de la Asociación Española de Amigos de la Arqueología, 34: 39-52.

Niso Lorenzo, J. y Loza Uriarte, M. (2011): "Yacimiento de San Martín de Dulantzi”. Arkeoikuska, 2011: 35-57.

Pablos Martínez, F.V. (2010): "Retorín (Seña-Tarrueza)". En M.L. Serna Gancedo, A. Martínez Velasco y V. Fernández Acebo (coords.): Castros y castra en Cantabria. Fortificaciones desde los orígenes de la Edad del Hierro a las guerras con Roma: catálogo, revisión y puesta al día. Santander: 525-530.

Padley, T.G. y Winterbottom, S. (1991): The wooden, leather and bone objects from Castle Street, Carlisle: excavations 1981-82. CWAAS, Research Series 5, 3. Kendal.

Palol Salellas, P. (1972); "Una tumba romana de Toledo y los frenos de caballo hispanos del Bajo Imperio". Pyrenae, 8: 133-146.

Palol, L. (1958): "Las excavaciones de San Miguel del Arroyo". Boletín del Seminario de Estudios de Arte y Arqueología, 24: 209-217.

Peralta Labrador, E. (2000): Los cántabros antes de Roma. Madrid.

Peralta Labrador, E.; Hierro Gárate, J.A. y Gutiérrez Cuenca, E. (2011): “Monedas de los campamentos romanos de campaña de las Guerras Cántabras del asedio de La Loma, Castillejo y El Alambre". Lucentum, 30: 151-172.

Pociña López, C.A. y Remolá Vallverdú, J.A. (2002): “A font monumental a carea portuaria de Tarraco. Notes preliminars". Empùries, 53: 41-47.

Quesada, F.; Gómez Cabeza, F.; Molinos Molinos, M. y Bellón Ruiz, J.P. (2005): "El armamento hallado en el campo de batalla de Las Albahacas-Baecula". En J.P. Bellón, A. Ruiz, M. Molinos, C. Rueda y F. Gómez (eds.): La Segunda Guerra Púnica en la Península Ibérica. Baecula. Arqueología de una batalla. Jaén: 317-396.

Requejo Pagés, O. (2000): "Primera necrópolis tardía en el territorio de los Astures Transmontani: el yacimiento de Paredes, Siero (Principado de Asturias, España)". Actas do $3^{\circ}$ Congresso de Arqueología Peninsular, vol. VI. Porto: 513-526.

Requejo Pagés, O. y Álvarez Martínez, V. (2008): “Materiales arqueológicos procedentes de la villa de Priañes, Nora, Oviedo, Principado de Asturias". Férvedes, 5: 405-412.

Rhodes, M. (1980): “Leather footwear". En D.M. Jones Excavations at Billingsgate Buildings 'Triangle', Lower 
Thames Street, 1974. London and Middlesex Archaeological Society Special Paper 4. Londres: 99-128.

Rhodes, M. (1986): "Leather objects". En D.M. Jones Excavations at Billingsgate Buildings 'Triangle', Lower Thames Street, 1974. London and Middlesex Archaeological Society Special Paper 4. Londres: 218-226.

Rodríguez Ceballos, M. (2016): La cueva de Román. Nuevas hipótesis para entender "Clunia Sulpicia”. Tesis Doctoral. Universidad de Alcalá de Henares. Madrid.

Rodríguez Morales, J.; Fernández Montoro, J.L.; Sánchez Sánchez, J. y Benítez de Lugo, L. (2012): “Los clavi caligarii o tachuelas de cáliga, elementos identificadores de las calzadas romanas". Lucentum, 31: 147-164. DOI: https://doi.org/10.14198/LVCENTVM2012.31.08

Ruiz Rodríguez, A.; Rueda Galán, C.; Bellón Ruiz, J.P. y Gómez Cabeza, F. (2013): "El factor ibero en la batalla de Baecula: los efectos colaterales de la guerra". Cuadernos de Prehistoria y Arqueología Universidad de Granada, 23: 199-225.

Schleiermacher, M. (1982): "Römische Leder- und Textilfunde aus Köln”. Archaologisches Korrespondezblatt, 12: 205-216.

Serna Gancedo, M.L. (2010): "Castro del Castillo de Prellezo (Prellezo, Val de San Vicente)”. En M.L. Serna Gancedo, A. Martínez Velasco y V. Fernández Acebo (coords.): Castros y castra en Cantabria. Fortificaciones desde los orígenes de la Edad del Hierro a las guerras con Roma: catálogo, revisión y puesta al día. Santander: 173-180.

Serna Gancedo, M.L. y Gómez Casares, G. (2010): "Estructura defensiva de Robadorio (Vega de Liébana-Boca de Huérgano)”. En M.L. Serna Gancedo, A. Martínez Velasco y V. Fernández Acebo (coords.): Castros y castra en Cantabria. Fortificaciones desde los orígenes de la Edad del Hierro a las guerras con Roma: catálogo, revisión y puesta al día. Santander: 121-126.

Serrula Rech, F.; Grandal D’Anglade, A.; Vilar Labarta, S. y Gómez, M. (2011): “Aproximación facial y paleodieta en un esqueleto de la necrópolis de El Vergel (Ávila-España)". Munibe, 62: 341-349

Studer, G. (2003): "Método de extracción de los materiales hallados en el puerto de Irún (Oiasso)". En R. Palacios Ramos (dir.): La conservación del material arqueológico subacuático. Monte Buciero 9. Santoña. 459-467.

Teira Brión, A.M.; Martín Seijo, M.; De Lombera Hermida, A.; Fábregas Valcarce, R. y Rodríguez Álvarez, X.P. (2012): "Forest resource management during Roman and Medieval cave occupations in the Northwest of the Iberian Peninsula Cova do Xato and Cova Eirós (Galicia, Spain)". Saguntum, Extra 13: 159-166.

Unzueta Portilla, M. y Ocharán Larrondo, J.A. (2006): "El campo de Batalla de Andagoste (Álava). Catálogo abreviado de monedas". En M.P. García-Bellido (coord.): Los campamentos romanos en Hispania (27 a.C.-192 d.C): el abastecimiento de moneda, 2. Madrid: 491-492.
Urteaga, M. (2005): "El puerto romano de Irún". Mar Exterior: el occidente atlántico en época romana. Roma: 85-106.

Urteaga, M. y Alkain, P. (2017-en prensa): “Calzado, tejidos y otras colecciones orgánicas romanas en Oiasso (Irún)". En A. Morillo, M. Hermanns y J. Salido (eds.): Arqueología "efimera". Productos y materiales perecederos en el registro arqueológico de época romana. Madrid.

Urteaga, M. y Arce, J. (2011): Arqueología romana en Gipuzkoa. Donostia-San Sebastián.

Urteaga, M. y Gereñu, M. (2003): "Planificación de las excavaciones arqueológicas en sedimentos inundados; la experiencia del centro de estudios Arkeolan". La conservación del material subacuático. Monte Buciero 9. Santoña: 431-457.

Urteaga, M. y Otero, X. (2002): Erromatar garaia. Bertan 15. San Sebastián.

Van Driel-Murray, C. (2001): "Footwear in the North-Western Provinces of the Roman Empire". Stepping through time. Archeological footwear from prehistoric times until 1800. Zwolle: 337-379.

Van Driel-Murray, C.V. (1965): “Die römerzeitlichen Schuh- und Lederfunde der Kastelle Saalburg, Zugmantel und Kleiner Feldberg". Saalburg Jahrbuch, 22: 158-210.

Van Driel-Murray, C.V. (1977): "Stamped leatherwork from Zwammerdam". En B.L. van Beek, R.W. Brandt y W. Groenman-van Waateringe (eds.): Ex horreo. Cingula 4. Amsterdam: 151-164.

Van Driel-Murray, C.V. (1977b): "Leatherwork". En J.K. Haalebos (ed.): Zwammerdam Nigrum Pullum: Ein Auxiliarkastell am Niedergermanischen Limes. Cingula 3. Amsterdam: 249-281.

Van Driel-Murray, C.V. (1999): Das Ostkastell von Welzheim, Rems-Murr-Kreis. Die römischen Lederfunde. Die Terra sigillata. Forschungen und Berichte zur Vor- und Frühgeschichte in Baden-Württemberg 42. Stuttgart.

Van Driel-Murray, C.V. (1999b): “Dead men's shoes". En W. Schlüter y R. Wiegels (eds.): Rom, Germanien und die Ausgrabungen von Kalkriese. Internationaler Kongress der Universität Osnabrück und des Landschaftsverbandes Osnabrücker Land. Osnabrück: 169189.

Van Driel-Murray, C.V. (2001): "Footwear in the North-Western Provinces of the Roman Empire". Stepping through Time: Archaeological Footwear from Prehistoric Times until 1800. Zwolle: 336-376.

Van Driel-Murray, C.V. (2001b): "Vindolanda and the dating of Roman footwear". Britannia, 32: 185-197. DOI: https://doi.org/10.2307/526955

Van Driel-Murray, C.V. y Gechter, M. (1983): "Funde aus der fabrica der legio I Minervia am Bonner Berg". Beiträge zur Archäologie des römischen Rheinlands, 4: 1-83.

Vanhoutte, S.; Bastiaens, J.; De Clecq, W.; Deforce, K.; Ervynck, A.; Fret, M.; Haneca, K.; Lentacker, A.; 
Stieperaere, H.; Van Neer, W.; Cosyns, P.; Degryse, P.; Dhaeze, W.; Dijkman, W.; Lyne, M.; Rogers, P.; Van Driel-Murray, C.; Van Heesch, J. y Wild, J.-P. (2009): "De dubbele waterput uit het laat-Romeinse castellum van Oudenburg (prov. West-Vlaanderen): tafonomie, chronologie en interpretatie". Relicta, 5: 9-142.

Vigil-Escalera Guirado, A. (2015): Los primeros paisajes altomedievales en el interior de Hispania: registros campesinos del siglo quinto d.C. Bilbao. 